\title{
Horizontal Cell Feedback to Cone Photoreceptors in Mammalian Retina: Novel Insights From the GABA-pH Hybrid Model
}

\section{OPEN ACCESS}

Edited by:

Wallace B. Thoreson,

University of Nebraska Medical

Center, United States

Reviewed by:

Michel Joseph Roux, INSERM U964 Institut de Génétique et de Biologie Moléculaire et

Cellulaire (IGBMC), France Wen Shen,

Florida Atlantic University, United States

*Correspondence: Steven Barnes sbarnes@doheny.org

Specialty section: This article was submitted to

Cellular Neurophysiology,

a section of the journal

Frontiers in Cellular Neuroscience

Received: 15 August 2020 Accepted: 24 September 2020 Published: 04 November 2020

Citation:

Barnes S, Grove JCR, McHugh CF, Hirano AA and Brecha NC (2020) Horizontal Cell Feedback to Cone Photoreceptors in Mammalian Retina: Novel Insights From the GABA-pH Hybrid Model. Front. Cell. Neurosci. 14:595064. doi: 10.3389/fncel.2020.595064

\author{
Steven Barnes ${ }^{1,2,3 *}$, James C. R. Grove ${ }^{4}$, Cyrus F. McHugh ${ }^{1}$, Arlene A. Hirano ${ }^{3,5}$ \\ and Nicholas C. Brecha ${ }^{3,5,6,7}$
}

${ }^{1}$ Doheny Eye Institute, Los Angeles, CA, United States, ${ }^{2}$ Department of Ophthalmology, David Geffen School of Medicine, University of California, Los Angeles, Los Angeles, CA, United States, ${ }^{3}$ Department of Neurobiology, David Geffen School of Medicine, University of California, Los Angeles, Los Angeles, CA, United States, ${ }^{4}$ Neuroscience Graduate Program, University of California, San Francisco, San Francisco, CA, United States, ${ }^{5}$ Veterans Administration Greater Los Angeles Healthcare System, Los Angeles, CA, United States, ${ }^{6}$ Department of Medicine, David Geffen School of Medicine, University

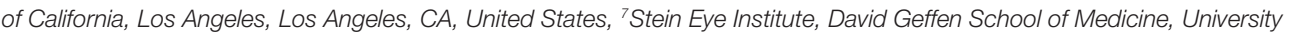
of California, Los Angeles, Los Angeles, CA, United States

How neurons in the eye feed signals back to photoreceptors to optimize sensitivity to patterns of light appears to be mediated by one or more unconventional mechanisms. Via these mechanisms, horizontal cells control photoreceptor synaptic gain and enhance key aspects of temporal and spatial center-surround receptive field antagonism. After the transduction of light energy into an electrical signal in photoreceptors, the next key task in visual processing is the transmission of an optimized signal to the follower neurons in the retina. For this to happen, the release of the excitatory neurotransmitter glutamate from photoreceptors is carefully regulated via horizontal cell feedback, which acts as a thermostat to keep the synaptic transmission in an optimal range during changes to light patterns and intensities. Novel findings of a recently described model that casts a classical neurotransmitter system together with ion transport mechanisms to adjust the alkaline milieu outside the synapse are reviewed. This novel inter-neuronal messaging system carries feedback signals using two separate, but interwoven regulated systems. The complex interplay between these two signaling modalities, creating synaptic modulation-at-a-distance, has obscured it's being defined. The foundations of our understanding of the feedback mechanism from horizontal cells to photoreceptors have been long established: Horizontal cells have broad receptive fields, suitable for providing surround inhibition, their membrane potential, a function of stimulus intensity and size, regulates inhibition of photoreceptor voltage-gated $\mathrm{Ca}^{2+}$ channels, and strong artificial pH buffering eliminates this action. This review compares and contrasts models of how these foundations are linked, focusing on a recent report in mammals that shows tonic horizontal cell release of $\mathrm{GABA}$ activating $\mathrm{Cl}^{-}$and $\mathrm{HCO}_{3}^{-}$permeable GABA autoreceptors. The membrane potential of horizontal cells provides the driving 
force for GABAR-mediated $\mathrm{HCO}_{3}^{-}$efflux, alkalinizing the cleft when horizontal cells are hyperpolarized by light or adding to their depolarization in darkness and contributing to cleft acidification via NHE-mediated $\mathrm{H}^{+}$efflux. This model challenges interpretations of earlier studies that were considered to rule out a role for GABA in feedback to cones.

Keywords: GABA receptor, horizontal cell, inhbitory feedback, photoreceptors, pH, center-surround inhibition, rho subunit, bicarbonate

\section{WHAT IS FEEDBACK TO PHOTORECEPTORS?}

Output signaling from photoreceptors takes place at synaptic complexes comprising the photoreceptor terminal, horizontal cell synaptic processes, and bipolar cell dendrites, where visual information transfer and processing is initiated (Thoreson and Mangel, 2012). Here, essential aspects of visual processing, including center-surround antagonistic receptive field formation, color opponency, and sensitivity to spatiotemporal change, rely on lateral inhibitory feedback to photoreceptors by horizontal cells (Baylor et al., 1971; Mangel, 1991; Burkhardt, 1993; Dacey et al., 2000; Twig et al., 2003). This feedback was recently characterized as "The Case of the Missing Neurotransmitter" (Kramer and Davenport, 2015), emphasizing that the mechanisms proposed to underlie this feedback neurotransmission are not simple, fully characterized, agreed upon, or well understood (Thoreson and Mangel, 2012).

The known common targets of horizontal cell feedback reported in virtually all vertebrate species are the voltagegated $\mathrm{Ca}^{2+}\left(\mathrm{Ca}_{\mathrm{V}}\right)$ channels in the photoreceptor synaptic terminal (Verweij et al., 1996, 2003; Hirasawa and Kaneko, 2003; Vessey et al., 2005; Cadetti and Thoreson, 2006). These channels are necessary for photoreceptors to release neurotransmitters in the same manner that $\mathrm{Ca}_{V}$ channels are necessary for release in most other neurons, where presynaptic depolarization activates $\mathrm{Ca}_{\mathrm{V}}$ channels, and this increases calcium influx that facilitates the release of neurotransmitter. However, photoreceptors hyperpolarize in response to light, meaning that during a light stimulus, the $\mathrm{Ca}_{\mathrm{V}}$ channels become less activated, glutamate release decreases, and postsynaptic horizontal cells hyperpolarize. Since the horizontal cells extend lateral processes broadly, they receive input from a large number of photoreceptors, and they hyperpolarize strongly to a spatially large light stimulus but produce only a small hyperpolarization to a small spot of light.

Partial inhibition of cone $\mathrm{Ca}_{V}$ channel activation is the base functional state in darkness. To appreciate how the inhibition changes in response to patterned light stimulation, we describe the steps in the photoreceptor response to light, including $\mathrm{Ca}_{\mathrm{V}}$ channel disinhibition during the response to a large spatial stimulus. In response to a brief, small spot of light, the cone hyperpolarizes, as seen in Figure 1. This is due to the lightinduced closure of cGMP-gated channels in the photoreceptor outer segment, resulting in a reduction of the depolarization produced by those non-selective cation channels, allowing the standing $\mathrm{K}^{+}$channel currents $\left(\mathrm{I}_{\mathrm{Kx}}\right)$ to hyperpolarize the cell, typically from about $-40 \mathrm{mV}$ to as much as $-60 \mathrm{mV}$. However, in response to a large spot of light, an identical hyperpolarization occurs initially but this is followed by inhibitory feedback from strongly hyperpolarized horizontal cells that produce a delayed depolarizing phase in the cone response. Confusing as it may seem, this depolarization is what was originally referred to as inhibitory feedback (since it was an inhibition of the hyperpolarizing response to light), but we currently recognize that the underlying mechanism is a disinhibition of the cone Cav channels.

In this review, we discuss feedback in terms of the mechanism at the level of the photoreceptor $\mathrm{Ca}_{\mathrm{V}}$ channels, and we refer to the terms "inhibition" and "disinhibition" in the context of horizontal cell modulation of photoreceptor voltage-gated $\mathrm{Ca}_{V}$ channels. For example, inhibition of cone $\mathrm{Ca}_{\mathrm{V}}$ channels occurs when horizontal cells are depolarized during steady-state conditions of darkness or low light. In earlier reports, before the role of cone $\mathrm{Ca}_{V}$ channels in feedback was established by Verweij et al. (1996), "inhibitory feedback" was (and remains in many reports) terminology referring not to cone $\mathrm{Ca}_{V}$ channels but to the delayed depolarization that occurs in response to added surround illumination, which reduces (or "inhibits") the

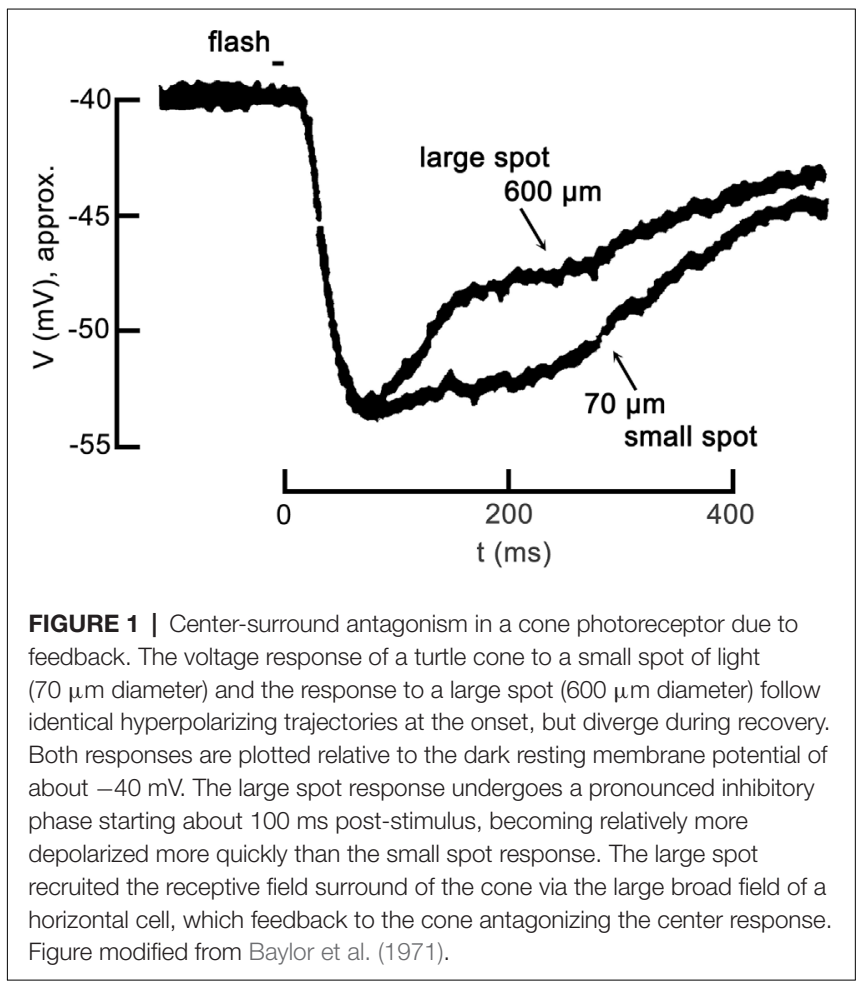


hyperpolarizing response to focal stimulation of a cone with light (Figure 1). However, we now appreciate that since surround illumination produces strong horizontal cell hyperpolarization, this phenomenon observed in the cone membrane potential is caused by a de facto disinhibition of the cone $\mathrm{Ca}_{\mathrm{V}}$ channels.

There is evidence for several feedback mechanisms, the most prominent of which include neurotransmitter-mediated signaling via GABA (or another/additional transmitter), interstitial current-induced external voltage changes, or "ephaptic coupling," and pH-mediated surface charge screening effects. While similar descriptions of feedback from horizontal cells to photoreceptors have been reported in the retinas of non-mammalian vertebrates, the fewer reports in mammalian species have to account for significant underlying mechanistic differences from non-mammalian species (Thoreson and Mangel, 2012; Liu et al., 2013). These differences between mammalian and non-mammalian species are important to note, as they have previously complicated attempts to understand this synaptic feedback circuit (Wu, 2010; Thoreson and Mangel, 2012; Liu et al., 2013; Kramer and Davenport, 2015).

\section{MECHANISMS OF FEEDBACK TO PHOTORECEPTORS}

\section{GABA}

The early detection of GABA in horizontal cells (Lam et al., 1978) propelled investigation into how horizontal cell release of GABA would mediate feedback. At the time, models presumed a simple inhibitory neural action and it seemed safe to assume that horizontal cells would release GABA when they are depolarized and that the released GABA would bind to presumptive GABARs on photoreceptors, increasing $\mathrm{Cl}^{-}$conductance, leading to photoreceptor hyperpolarization. Even then such a mechanism for GABA was difficult to reconcile since, as a starting point, either the hyperpolarized horizontal cell had to release a transmitter that produced a sign-inverting depolarization in the cone associated with a conductance increase, or the horizontal cell had to release a neurotransmitter that decreased conductance in cones in the dark, and when reduced by light, this led to increased cone conductance (Baylor et al., 1971). Later reports continued to support a role for horizontal cell release of GABA (Cueva et al., 2002; Hirano et al., 2005, 2016; Guo et al., 2010). In mammalian retinas, compelling evidence suggests that horizontal cells release GABA in a depolarization-dependent, vesicular manner (Hirano et al., 2016; Grove et al., 2019). In mammals, GABA and the GABA synthetic enzyme, L-glutamate decarboxylase (GAD) are localized to horizontal cells (Schnitzer and Rusoff, 1984; Wässle and Chun, 1989; Grünert and Wässle, 1990; Vardi et al., 1994; Guo et al., 2010; Schubert et al., 2010; Deniz et al., 2011) and VGAT, V-ATPase, multiple SNARE, and vesicle proteins, and $\mathrm{Ca}_{\mathrm{V}}$ channels mediating vesicular release are localized to horizontal cell dendritic tips and axonal terminals (Dowling and Boycott, 1966; Brandon and Lam, 1983; Linberg and Fisher, 1988; Peters et al., 1991; Catsicas et al., 1992; Ueda et al., 1992; Löhrke and Hofmann, 1994; Grabs et al., 1996; Greenlee et al., 2001; Rivera et al., 2001; Cueva et al., 2002;
Hirano et al., 2005, 2007, 2011; Schubert et al., 2006; Lee and Brecha, 2010; Liu et al., 2013). Furthermore, vesicle membrane fusion and recycling in horizontal cells is depolarization-and $\mathrm{Ca}^{2+}$-dependent (Takamori et al., 2000; Vuong et al., 2011), and the deletion of VGAT from horizontal cells abolishes horizontal cell inhibitory feedback to photoreceptor $\mathrm{Ca}_{\mathrm{V}}$ channels (Hirano et al., 2016). This evidence leads to the conclusion that depolarization-mediated, $\mathrm{Ca}^{2+}$-dependent GABA release could mediate horizontal cell signaling. However, due to several additional observations, including the low concentration of vesicles in horizontal cells synaptic terminals, and the persistent GABA presence around horizontal cell synaptic endings, it has been suggested that GABA release could be continuous, increasing with depolarization, but slowly and with limited uptake and degradation in the synaptic cleft (Grove et al., 2019).

The existence of many similar features of feedback in mammalian and non-mammalian vertebrates suggests conservation of mechanisms but may serve as false flags when making comparisons, and there are critical differences concerning GABA. (1) Non-mammalian vertebrates have not been proven to have a GABA vesicular release mechanism in horizontal cells similar to that in mammals. Instead, early discoveries in several non-mammalian vertebrates concluded that reversed GABA-uptake transporters in horizontal cells mediate the release of GABA (Schwartz, 1982, 1987, 2002; Yazulla and Kleinschmidt, 1983; Ayoub and Lam, 1984). Mammalian horizontal cells do not have GABA-uptake transporters (GATs; Johnson et al., 1996; Guo et al., 2009, 2010), so they do not emulate this mechanism of action. (2) While non-mammalian vertebrates also appear to have GABA in some of their horizontal cells, many have been reported to not contain GABA and some may employ different neurotransmitters. This said, there are important similarities. Both types of vertebrates have GABA receptors on their horizontal cells and both have elevated chloride equilibrium potentials (around $-30 \mathrm{mV}$ ). These similarities suggest that vertebrates may employ the same GABA-pH hybrid mechanism, albeit with a different means of GABA release, the details of which are discussed extensively in the body of this review.

In non-mammalian species, horizontal cell release of GABA appears to directly hyperpolarize photoreceptors (Skrzypek and Werblin, 1983; Tachibana and Kaneko, 1986; Wu, 1991, 1994; Tatsukawa et al., 2005; Endeman et al., 2012). In contrast, a direct action of GABA on photoreceptors has not been unequivocally established in mammals. Many physiological recordings in the normal mammalian retina do not show a direct action of GABAergic agents on cones (Verweij et al., 2003; Crook et al., 2009; Kemmler et al., 2014; Szikra et al., 2014; Grove et al., 2019), but there is evidence for GABAR subunit expression by mammalian photoreceptors (Greferath et al., 1993; Grigorenko and Yeh, 1994; Picaud et al., 1998; Vardi et al., 1998; Chaffiol et al., 2017). However, in cultured retinal explants (and possibly in $\mathrm{rd} 1$ mice lacking rods), cones may be reprogrammed and respond to GABA application (Picaud et al., 1998; Pattnaik et al., 2000), and one report indicates GABA activation of TPMPAinsensitive GABAR $\mathrm{Cl}^{-}$channels in wild-type mouse cones (Deniz et al., 2019). Further complicating the functional role 
for photoreceptor $\mathrm{Cl}^{-}$flux, during surround light stimulation that hyperpolarizes horizontal cells, the resulting disinhibition of $\mathrm{Ca}_{\mathrm{V}}$ channels in cones in fish (Verweij et al., 1996) and macaque (Verweij et al., 2003) is accompanied by an increase in $\mathrm{Ca}^{2+}$-activated $\mathrm{Cl}^{-}$conductance. These events are not easily reconcilable with a direct ionotropic GABA action in cones and would be more confidently considered to be due to a reduction of $\mathrm{Cl}^{-}$conductance during reduced GABA release by horizontal cells.

An additional long-standing controversial issue was that GABA release by depolarized horizontal cells directly mediating feedback to cones required an atypical mechanism. Baylor et al. (1971) suggested that the inhibition of the light response defied any known neurotransmitter mechanism. Horizontal cell hyperpolarization leads to cone depolarization, which is associated with a conductance increase. A solution, reviewed here, is that horizontal cell feedback signaling is mediated by GABA acting indirectly on photoreceptors. This is supported by findings that GABA acts autaptically on horizontal cells, whose depolarization and membrane properties result in $\mathrm{pH}$-regulated inhibition of photoreceptor $\mathrm{Ca}_{\mathrm{V}}$ channels (Liu et al., 2013; Grove et al., 2019).

Since horizontal cell feedback affects cone synaptic output to bipolar cells, horizontal cell influences carry through to these cells. Also, horizontal cells appear to inhibit directly the dendrites of many types of bipolar cells. Horizontal cell signaling mediated by GABA to bipolar cells is consistent with GABARs on bipolar cell dendrites (Vardi et al., 1992; Enz et al., 1996; Wässle et al., 1998; Haverkamp and Wässle, 2000; Haverkamp et al., 2000; Hoon et al., 2015), although which bipolar cell types and their complement of dendritic GABAR subtypes are unknown (Chaffiol et al., 2017). Different $\left[\mathrm{Cl}^{-}\right]_{\mathrm{i}}$ levels in bipolar cell dendrites, maintained by two types of chloride co-transporters (KCC2 and NKCC; Vardi et al., 2000; Vu et al., 2000) could account for a direct inhibitory and excitatory effect caused by GABA released by horizontal cells at ON- and OFF-bipolar cells (Miller and Dacheux, 1983; Satoh et al., 2001; Varela et al., 2005; Duebel et al., 2006). Both feedback via cones and direct feedforward signaling pathways have a strong influence on bipolar cell responsiveness and all downstream neurons in the retina and visual system.

\section{Ephaptic Coupling and the Role of Hemichannels}

The unique, enveloping structural constraints of this synapse, where horizontal cell synaptic endings invaginate rod and cone presynaptic terminals led to the proposal of the "electric feedback model" as the mechanism of feedback (Byzov, 1977; Byzov et al., 1977; Byzov and Shura-Bura, 1986). This model was based on the fact that current flow through a resistive medium (here, the tortuous extracellular paths through which current flows to enter glutamate receptor channels in the synaptic endings), constitutes a resistance, which according to Ohm's law creates a voltage drop at the horizontal cell synaptic tips. The result is a net negative extracellular voltage in the synaptic cleft relative to ground $(0 \mathrm{mV})$. By producing an external negative potential here, outside the cone membrane at the synaptic release site, the electric field across the membrane of the adjacent cone is reduced, affecting equivalent to depolarization of the cone membrane that increases the activation of the photoreceptor $\mathrm{Ca}_{V}$ channels responsible for glutamate release (Taylor and Morgans, 1998; Nachman-Clewner et al., 1999; Morgans, 2001). The physics of this model is solid, but there is a lack of certainty of the amplitude of the external voltage drop, and more troubling for the model, when the horizontal cell glutamateactivated postsynaptic current is reduced during a strong light stimulus, hyperpolarizing the cell, interstitial current flow to the synapse is reduced, and feedback modulation is diminished or even vanishes.

Decades later, Kamermans et al. (2001) solved this dilemma, upgrading Byzov's model (Byzov, 1977; Byzov et al., 1977; Byzov and Shura-Bura, 1986) by incorporating the finding that hemichannels, each half of a gap junction channel and composed of connexin26, had been identified at the tips of fish horizontal cell dendrites deep within the invagination (Janssen-Bienhold et al., 2001a,b). This clever improvement circumvented the perceived problems caused by the closure of glutamate-gated channels by invoking the presence of ion channels that were not gated by glutamate and that would reliably produce the interstitial current flow required for continuous extracellular non-zero voltage modulation. According to this new hemichannel hypothesis, surround illumination that causes strong horizontal cell hyperpolarization and greater inward current through hemichannels in their synaptic endings (Kamermans et al., 2001; Fahrenfort et al., 2005), producing a voltage drop in the synaptic cleft. While interstitial voltage cannot be reliably measured, this action is revealed in voltage-clamped cones during surround illumination, acting as a shift in the activation curve of the cone $\mathrm{Ca}_{V}$ channel current to more positive potentials (Verweij et al., 1996, 2003) increasing glutamate release, this being the feedback that opposes the cone hyperpolarization.

Hemichannels at the photoreceptor synapse were found in goldfish, zebrafish, and turtles on the membranes of the lateral processes of horizontal cell tips, deep within the synaptic terminal (Kamermans et al., 2001; Pottek et al., 2003; Klaassen et al., 2011). Pharmacological blockade of hemichannels with carbenoxolone blocked feedback-mediated responses in non-mammalian cones and horizontal cells (Kamermans et al., 2001). According to the model, by blocking hemichannels, carbenoxolone restores the suppression of cone $\mathrm{Ca}_{V}$ channels through an apparent rightward shift of the activation curve, reducing the amount of glutamate is released. It should be noted that while carbenoxolone has been widely used as a functional probe for gap junctions, this diagnostic tool depends entirely on the specificity of its actions, and there are reports it can act on multiple targets. In addition to blocking gap junctions, carbenoxolone has been shown to suppress action potentials, decrease input resistance, block $\mathrm{Ca}_{\mathrm{V}}$ channels, block postsynaptic NMDA receptors, and reduce inhibitory synaptic currents through a direct effect on GABARs (Rekling et al., 2000; Rouach et al., 2003; Vessey et al., 2004; Tovar et al., 2009; Beaumont and Maccaferri, 2011; Connors, 2012). Thus, the 
effects of carbenoxolone do not constitute conclusive evidence that gap junctions are involved, especially when GABARs and $\mathrm{Ca}_{\mathrm{V}}$ channels are involved.

The hemichannel model was bolstered by comparing normal and genetically modified zebrafish that lack connexin hemichannels in horizontal cells (Klaassen et al., 2011). Feedback was reduced in the mutants, supporting the hemichannel role in feedback from horizontal cells to cones. Intracellular recordings in horizontal cells showed coloropponent responses were diminished and the mutant fish also showed decreased contrast sensitivity in behavioral tests, expanding the reach of the model to the functional level in visual processing.

The role of hemichannels in horizontal cell feedback in zebrafish was further expanded to include $\mathrm{pH}$ effects at the synapse. In addition to connexin hemichannels mediating rapid feedback actions, pannexin hemichannels are implicated in ATP release, which induces extracellular acidification through hydrolysis of ATP by endonucleotidases in the cleft (Kurtenbach et al., 2014; Vroman et al., 2014). Pannexin/ATP-mediated feedback is a $\mathrm{Ca}_{V}$ channel inhibiting mechanism occurring with depolarization of the horizontal cell, while connexinmediated feedback produces disinhibition when horizontal cells are hyperpolarized.

Physics sets the time course of hemichannel mediated ephaptic feedback, and it must occur instantly in response to changes in current flow in the glutamate-gated or hemichannel conductances, which for both depends on the horizontal cell membrane potential, regulated primarily by changes in glutamate levels in the cleft. The speed of feedback signaling has been used as a diagnostic tool, but it remains difficult to discriminate between models due to the layering of their actions.

As is the case with GABA, there are many differences between mammalian and non-mammalian retinas concerning hemichannels. Connexin hemichannels are not found in mammalian (rodent) horizontal cell tips. Analysis of pannexins in mouse horizontal cells shows sparse localization away from the invaginating tips of the horizontal cells (Kranz et al., 2013).

\section{Photoreceptor Synapse Modulation by pH}

Over many decades an appreciation has emerged that extracellular $\mathrm{pH}\left(\mathrm{pH}_{\mathrm{o}}\right)$ fluctuates in healthy brain tissues. Assessment of $\mathrm{pH}$ homeostasis in the vertebrate retina showed significant disparities from the earlier conception that $\mathrm{pH}_{\mathrm{o}}$ was one of the best-regulated homeostatic variables necessary for brain function (Yamamoto et al., 1992; Dmitriev and Mangel, 2004; Dmitriev et al., 2016). Not only did retinal measurements of $\mathrm{pH}_{\mathrm{o}}$ reveal values far from the $\mathrm{pH} 7.4$ seen in the vasculature, but $\mathrm{pH}_{\mathrm{o}}$ in the retina changed dramatically, depending on light stimulation, showing that the dynamic nature of $\mathrm{pH}_{\mathrm{o}}$ in tissue with high energy consumption exceeds those in other nervous and somatic tissues. In the retina, $\mathrm{pH}_{\mathrm{o}}$ is most acidic in the dark within the outer nuclear layer (ONL_composed of the cell bodies of rod and cone photoreceptors; Figure 2), with Müller cell processes. At the level of the retinal pigmented epithelium (RPE), $\mathrm{pH}$ increases, approaching that of the blood ( $\mathrm{pH} 7.4$ ) owing to the proximity of the choroidal supply. At the nerve fiber (NF) layer and ganglion cell (GC) bodies, $\mathrm{pH}$ also increases, presumably due to the voluminous and unimpeded buffering capacity provided by the aqueous humor, to a value near 7.2. What is more profound about this spatial disparity, is that under light-adapted conditions, the bulk $\mathrm{pH}$ increases at all layers across the retina, and the point of greatest change is the ONL, where the mitochondria of rods and cones are maximally active in the dark, and reduced in bright light, nearly completely in the case of rods at least, when they are hyperpolarized.

This spatiotemporal pattern of $\mathrm{pH}_{\mathrm{o}}$ reflects energy use by the cells. For example, in mouse rods, to maintain tonic depolarization, a high energy demand exists for the removal of $\mathrm{Na}^{+}$entering through $\mathrm{CNG}$ channels and $\mathrm{Na}^{+} /\left(\mathrm{Ca}^{2+}+\mathrm{K}^{+}\right)$exchangers of the outer segment, and replenishment of $\mathrm{K}^{+}$that effluxes via these and voltage-gated $\mathrm{Kx}$ channels of the inner

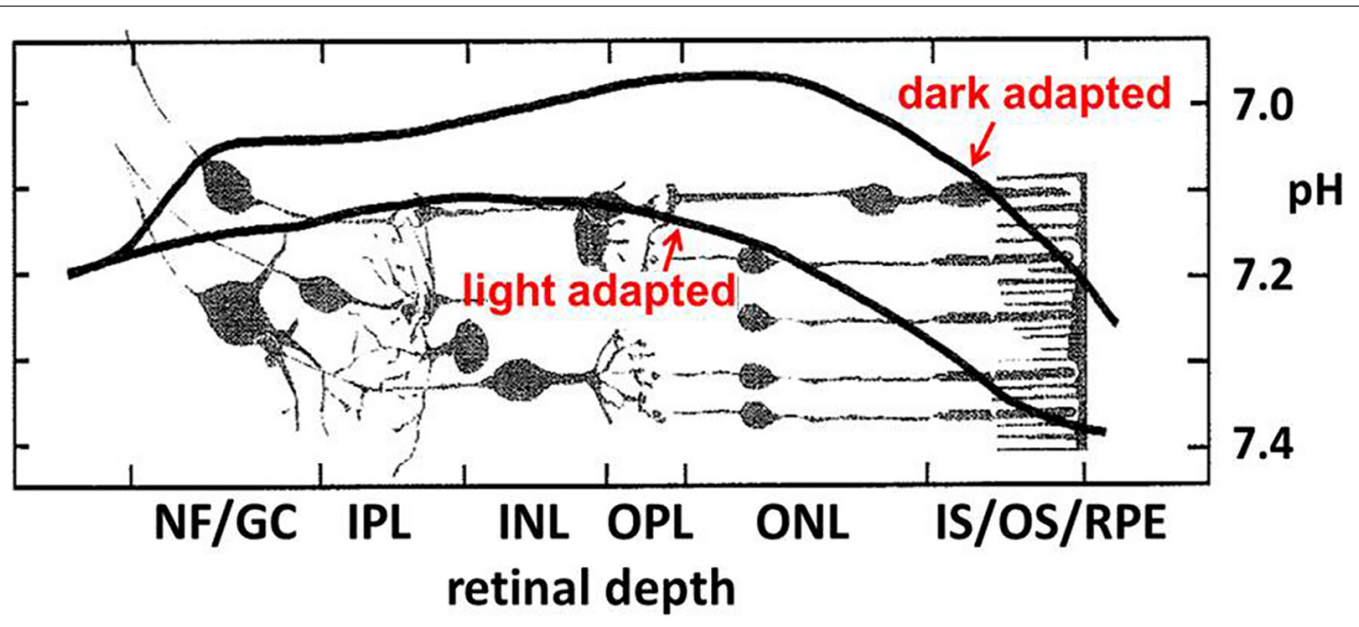

FIGURE 2 | Near the photoreceptor layer, there is a notable light vs. dark difference in bulk pHo in the outer retina. In the darkness, when rod and cone photoreceptors are maximally depolarized for an extended period, the pH becomes more acidic. Figure adapted from Yamamoto et al. (1992). 
segment, and pumping of $\mathrm{Ca}^{2+}$ from the synaptic terminal. ATP use in mouse rods is increased by a factor of 5 in the dark compared to bright light, with most of this due to increased $\mathrm{Na}^{+} / \mathrm{K}^{+}$-ATPase and $\mathrm{Ca}^{2+}$-ATPase activity (Krizaj and Copenhagen, 2002; Okawa et al., 2008). In general, when neurons are depolarized their ion channels are more frequently open (except some inward rectifier K and HCN channels) and their metabolic activity increases to maintain concentration gradients for $\mathrm{Na}^{+}, \mathrm{K}^{+}, \mathrm{Ca}^{2+}$, and other ions. The active transport of these ions by the $\mathrm{Na}^{+} / \mathrm{K}^{+}$-ATPase and plasma membrane $\mathrm{Ca}^{2+}$ ATPase is acknowledged to be the largest energy expenditure for neurons (Ames et al., 1992; Niven and Laughlin, 2008). At excitatory synapses where $\mathrm{Na}^{+}$influx and $\mathrm{K}^{+}$efflux can be protracted, and especially so in the present case where second-order neurons such as horizontal cells are in a tonically depolarized state during low illumination due to the continuous release of glutamate from photoreceptors, the energy cost of active ion transport to maintain transmembrane ion gradients are high (Wong-Riley, 2010). Thus, the energy requirements of the retina are higher in the dark than in the light, and in producing ATP, the neurons extrude $\mathrm{H}^{+}$prodigiously, making $\mathrm{pH}_{\mathrm{o}}$ low (Ames et al., 1992). It has long been appreciated that the high metabolic requirements and their dependence on illumination contribute to the sustained, low bulk $\mathrm{pH}$ in the outer retina in the dark and its increase during illumination (Borgula et al., 1989; Oakley and Wen, 1989; Yamamoto et al., 1992). Given this backdrop of $\mathrm{pH}_{\mathrm{o}}$ in the outer retina, it is noteworthy that an additional mechanism underlying feedback inhibition involves the regulation of $\mathrm{pH}_{\mathrm{o}}$ in the photoreceptor synaptic cleft (Thoreson and Mangel, 2012; Vroman et al., 2014; Wang et al., 2014; Beckwith-Cohen et al., 2019). Changes in $\mathrm{pH}_{\mathrm{o}}$ provide powerful modulation of voltage-gated ion channels due to membrane surface charge effects. This biophysical action occurs due to protons interacting with the fixed negative surface charge of the bilayer and membrane proteins, altering the electric field sensed by the voltage-sensors of ion channel proteins present in the membrane, leading in the present case to reduced photoreceptor $\mathrm{Ca}_{\mathrm{V}}$ activation (Hille, 1968; Barnes and Bui, 1991; Barnes et al., 1993). Increased $\mathrm{pH}$ buffering of the retina with Hepes suppresses feedback and concentrations as low as $10 \mathrm{mM}$ are enough to reversibly block it (Barnes et al., 1993; Hirasawa and Kaneko, 2003; Vessey et al., 2005; Cadetti and Thoreson, 2006; Davenport et al., 2008; Thoreson et al., 2008; Fahrenfort et al., 2009; Liu et al., 2013).

Shifts in synaptic cleft $\mathrm{pH}$ modulate the voltage dependence of photoreceptor $\mathrm{Ca}_{\mathrm{V}}$ channel activation and this regulates glutamate release from photoreceptors (Barnes et al., 1993; Cadetti and Thoreson, 2006; Babai and Thoreson, 2009). This clear and simple relationship demonstrates how activity-driven changes in $\mathrm{pH}$ in the synaptic cleft can affect synaptic regulation (Figure 3). Whether adaptations to the expression of $\mathrm{Na}^{+} / \mathrm{H}^{+}$ exchangers (NHEs), $\mathrm{HCO}_{3}^{-}$transporters (NBCs, AEs, NCBEs, and NDCBEs), V-ATPases, monocarboxylic acid transporters (MCTs) and carbonic anhydrase (CA; Soto et al., 2018), have occurred in the outer retina to mitigate or potentiate the contribution of acidification to this feedback mechanism is not known.

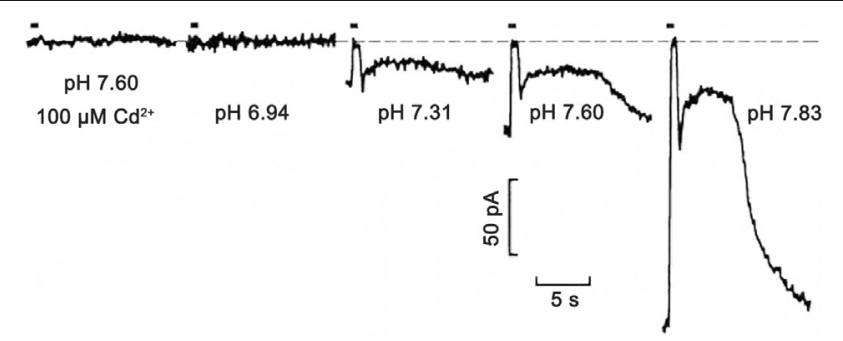

FIGURE 3 | Extreme pH sensitivity of synaptic transmission from photoreceptors to horizontal cells. Light responses to $500 \mathrm{~ms}$ bright light steps measured in a salamander horizontal cell under voltage-clamp were fully blocked at $\mathrm{pH} 6.94$, to the same extent as in the presence of Cav channel $100 \mu \mathrm{M} \mathrm{Cd}^{2+}$ at $\mathrm{pH}$ 7.6. Zero current is shown by the dashed line. As $\mathrm{pH}$ was increased to $7.31,7.60$, and 7.83 , the postsynaptic, light-induced glutamate-gated current changes were produced by the hyperpolarizing cone light responses (in the figure, the short up-going currents aligned with light stimulus timing bar) and rod response (slower and longer upward deflections) become larger. This is due to the turnoff by the light of the increased glutamate release in the dark. The exponentially increasing response amplitudes at increasing $\mathrm{pH}$ levels were shown to be due to surface charge screening effects on the voltage-gated Cav channels in presynaptic photoreceptors. Figure modified from Barnes et al. (1993).

As a final introductory remark, we highlight the remarkably potent effects that extracellular $\mathrm{pH}$ has on $\mathrm{Ca}_{\mathrm{V}}$ channel activation and gating, which is shared in all tissues and all species (Barnes et al., 1993; Neumaier et al., 2015). Changes in extracellular $\mathrm{pH}$ produce changes in the voltage-dependent activation of ion channels, due to the change in proton concentration causing differing degrees of proton adsorption to the fixed negative surface charge of the lipid bilayer proteins and binding to exposed ion channel protein amino acid side groups. The extreme proximity of protons to the surface of the cell membrane alters the electric field sensed by the ion channel voltage sensors, in effect adjusting their activation point at a given membrane potential (Barnes et al., 1993). Increased positive surface charge adsorption, as produced by decreased $\mathrm{pH}_{\mathrm{o}}$ (i.e., increased $\left[\mathrm{H}^{+}\right]_{\mathrm{o}}$ ) alters the electric field in the membrane acting upon the channel voltage sensor moves, producing the same action that a more negative membrane potential does, i.e., decreasing the probability of channel opening and moving the measured half-maximal activation voltage to more positive potentials. The relation between the $\mathrm{pH}$ and activation midpoint shift is on the order of a $1 \mathrm{pH}$ unit decrease causing a $10 \mathrm{mV}$ negative shift of $\mathrm{V}_{\frac{1}{2}}$ (Barnes et al., 1993). This means that a greater degree of membrane depolarization is required to activate ion channels under increasingly acidic extracellular pH's. This is how synaptic cleft $\mathrm{pH}$ alterations at the photoreceptor output synapse can potently alter the postsynaptic signals in horizontal and bipolar cells.

Accommodating these foundations, a new model based on the specific properties of horizontal cells in the mammalian retina, including the now-established release of GABA by horizontal cells (Hirano et al., 2016; Grove et al., 2019), demonstrated that horizontal cell-released GABA acts back, autaptically, on horizontal cell GABA receptors, and due to their intrinsic permeability to $\left[\mathrm{HCO}_{3}^{-}\right]$, facilitates its efflux, which modulates 
photoreceptor transmitter release via $\mathrm{pH}$ changes in the synaptic cleft (Liu et al., 2013; Grove et al., 2019). Also, especially given the richness of investigations in non-mammalian species (Byzov and Shura-Bura, 1986; Verweij et al., 1996; Kamermans et al., 2001; Vessey et al., 2005; Jackman et al., 2011; Klaassen et al., 2011; Kramer and Davenport, 2015) there may be other pathways by which horizontal cells affect photoreceptors (Kemmler et al., 2014).

\section{Cav CHANNELS IN MAMMALIAN CONES ARE TONICALLY MODULATED IN A GABA- AND pH-DEPENDENT MANNER}

The targets of horizontal cell feedback in photoreceptors are the voltage-gated $\mathrm{Ca}_{V}$ channels that mediate glutamate release from the presynaptic terminals (Verweij et al., 1996, 2003; Hirasawa and Kaneko, 2003; Vessey et al., 2005; Cadetti and Thoreson, 2006; Montgelard et al., 2008; Thoreson et al., 2008). While different mechanisms of feedback may dominate: (1) in specific species; (2) under different conditions of ambient illumination; and (3) over distinct temporal domains, here we will examine mechanisms operating under mesopic conditions using mammalian (rodent) retinas under this steady-state lighting condition (Grove et al., 2019). Due to earlier work showing a role for GABA in feedback, and with vesicular GABA release by horizontal cells being perhaps the most obvious difference between mammalian and non-mammalian horizontal cells, we review evidence for the role of GABA in the inhibition of mammalian photoreceptor $\mathrm{Ca}_{\mathrm{V}}$ channel activation. The component actions reviewed below allow dissection of the sequential mechanisms underlying features of feedback by probing the steady-state response of cones and horizontal cells, under constant conditions of illumination, as a baseline to identify mechanisms underlying feedback.

First, to what extent are GABARs involved in the steady-state inhibition of cone $\mathrm{Ca}_{\mathrm{V}}$ channels? The $\mathrm{Ca}_{\mathrm{V}}$ channel currents of cones patch-clamped in retinal slices were found to be increased by about $60 \%$ in mice, $40 \%$ in rats, and $25 \%$ in guinea pigs when the non-competitive ionotropic GABAR antagonist picrotoxin was superfused at $100 \mu \mathrm{M}$. Figure 4 shows these results from rat retina, with the amplitude of $\mathrm{Ca}_{\mathrm{V}}$ channel currents increased in the raw current traces, in response to voltage command steps, as well as in the current-voltage (I-V) relations made from these currents under the two conditions. When the I-V relations were divided by the driving force for $\mathrm{Ca}^{2+}$ and fit with a Boltzmann function to define the $\mathrm{Ca}_{V}$ channel activation curves, it was found that the half-maximal activation voltage shifted in mice, rats, and guinea pigs to a $\sim 5 \mathrm{mV}$ more negative voltage. A shift of the channel activation curve to more negative potentials in picrotoxin represents the disinhibition of cone $\mathrm{Ca}_{\mathrm{V}}$ channel currents as channel open probability increases at physiological membrane potentials. These results imply that
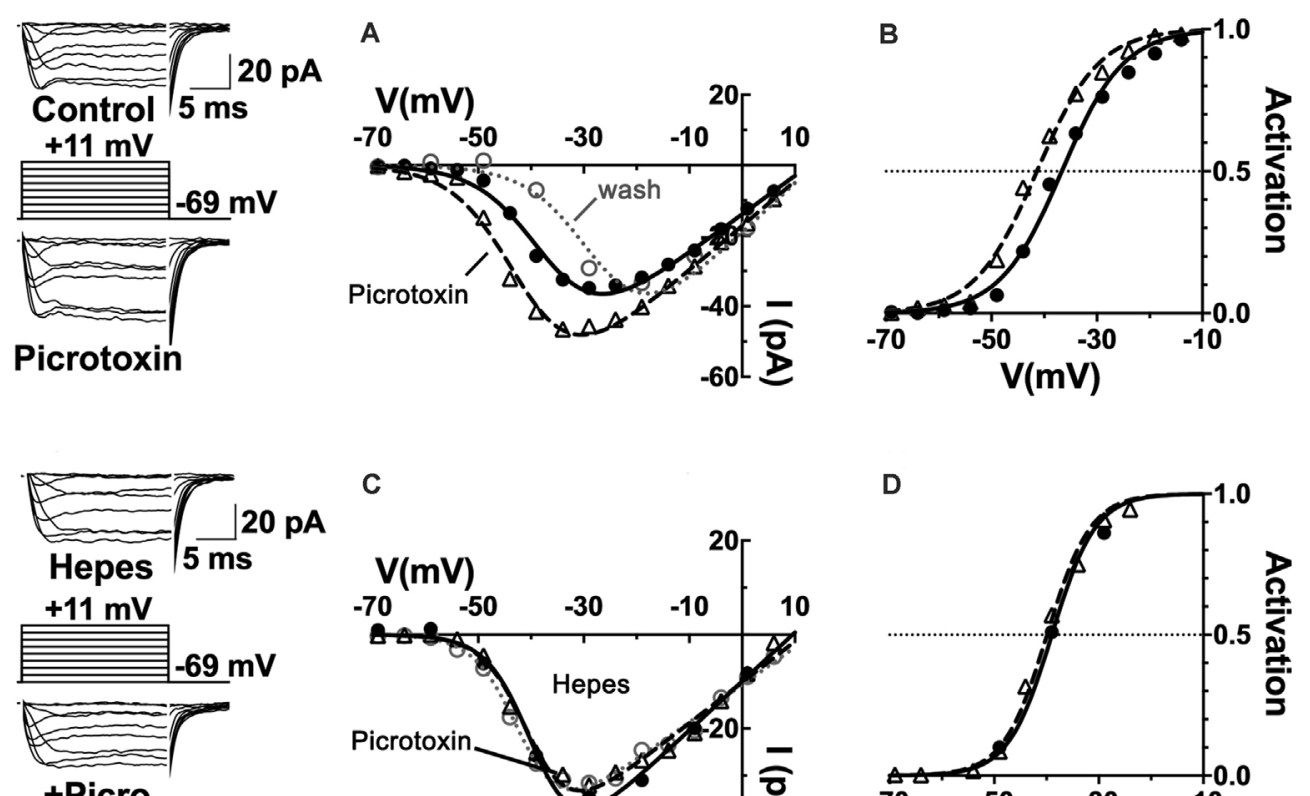

C
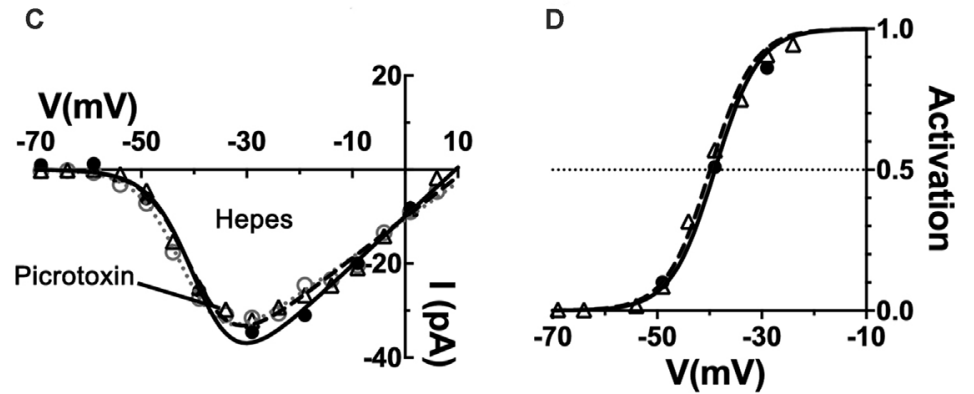

FIGURE 4 | Cav channels in mammalian cone photoreceptors are maintained in a pH-mediated, tonically inhibited state by GABA receptor activation. (A) The $\mathrm{GABA}_{A} \mathrm{R}$ antagonist picrotoxin increased calcium current amplitude in cones, maintained in mesopic conditions. Sample current traces and I-V relations of a rat cone before (solid line, filled circles), during (dashed line, triangles), and after (dotted line, open circles) application of $100 \mu \mathrm{M}$ picrotoxin to the retinal slice. (B) The Cav channel activation curve for the cell underwent a leftward shift in the half-maximal activation voltage in picrotoxin (midpoint $=-41 \mathrm{mV}$ ) vs. control (midpoint $=-37 \mathrm{mV}$ ). (C) Same experimental protocol as above applied while clamping superfusate $\mathrm{pH}$ to 7.4 with $10 \mathrm{mM}$ Hepes. $1-\mathrm{V}$ relation in Hepes alone is shown (solid line, circles) and then with picrotoxin (dashed line, triangles). Washout superimposes (dotted line, open circles). (D) Hepes eliminated the effect of picrotoxin on Cav channel activation (midpoint $=-39 \mathrm{mV}$ ). Figure modified from Grove et al. (2019). 
there is tonic GABA inhibition of cone $\mathrm{Ca}_{V}$ channels under mesopic conditions in these species.

The observation that horizontal cells inhibit photoreceptor output by shifting their $\mathrm{Ca}_{V}$ channel activation curves is consistent with earlier proposals (Verweij et al., 1996, 2003; Kamermans et al., 2001). The vital distinction is that these data show an unappreciated role for the transmitter GABA as well. The classical role of GABA in feedback, as shown through the antagonism by picrotoxin observed in fish cones (Endeman et al., 2012) involves direct activation of GABARs on cones, which is not an action seen in Figure 4, where no change in steadystate conductance of a $\mathrm{Cl}^{-}$current was noted. Picrotoxin blocks the ion channel pore of ionotropic $\mathrm{GABA}_{\mathrm{A}}$ receptors (Ashiya et al., 1995), as well as glycine receptors (Johnston, 2014), and does not affect $\mathrm{Ca}_{\mathrm{V}}$ channels per se. It did not decrease standing cone conductance that would have been present if GABA had been activating photoreceptor $\mathrm{Cl}^{-}$channels. No difference was observed in cone membrane conductance measured between -80 and $-50 \mathrm{mV}$ with and without picrotoxin in mice, rats, or guinea pigs, suggesting that the absence of a tonic, direct GABAergic input onto GABARs expressed in photoreceptors (Grove et al., 2019).

It bears mentioning that the results obtained in the fish retina were obtained using transient light flashes in a dark-adapted state, not the steady state mesopic conditions in Figure 4. The fact that the component action shown here is occluded when interstitial $\mathrm{pH}$ is clamped with the $\mathrm{pH}$ buffer Hepes (Figure 4), is interpreted as picrotoxin changing $\mathrm{pH}$ to modulate photoreceptor $\mathrm{Ca}_{\mathrm{V}}$ channels. The $\mathrm{pH}$ sensitivity of horizontal cell feedback and photoreceptor $\mathrm{Ca}_{V}$ channels (Hirasawa and Kaneko, 2003; Vessey et al., 2005; Cadetti and Thoreson, 2006; Thoreson et al., 2008; Vroman et al., 2014; Warren et al., 2016a), together with reports in mammals regarding the actions of GABA antagonists in the rat (Liu et al., 2013), guinea pig, mouse (Grove et al., 2019) and macaque (Verweij et al., 2003), connect this action of GABA to the change of cleft $\mathrm{pH}$.

Earlier suggestions that Hepes stifles feedback by acidifying the cytoplasm of all local neurons, and that due to that, the true mechanism of feedback cannot be sustained (Fahrenfort et al., 2009). This argument failed when results of numerous other pH-buffers (Davenport et al., 2008), as well as increased $\left[\mathrm{HCO}_{3}^{-}\right]$ (Vessey et al., 2005), were found to have the same effects on feedback, but without cytoplasmic acidification. A more recent theory that cleft $\mathrm{pH}$ changes are due instead to hydrolysis of ATP released via pannexin hemichannels (Vroman et al., 2014; Cenedese et al., 2017), is consistent with the effect of Hepes, however, the theory is mute in mammals since pannexins are not present at horizontal cell endings in the synaptic invagination (Kranz et al., 2013).

\section{WHAT TYPE OF GABA RECEPTORS ARE RESPONSIBLE FOR THIS UNCONVENTIONAL EFFECT?}

GABA receptors containing $\rho$-subunits (a.k.a. GABA $\mathrm{G}_{\mathrm{C}} \mathrm{R}$ ) appear to play the central role in the modulation of the cone $\mathrm{Ca}_{V}$ channel currents. The $\rho$-subunit-containing GABAR inhibitor TPMPA, the $\mathrm{GABA}_{\mathrm{A}} \mathrm{R}$ inhibitor gabazine, and the glycine receptor inhibitor strychnine were tested for their ability to produce $\mathrm{Ca}_{V}$ channel activation curve shifts in cones, and only TPMPA produced activation shifts. This result identified $\rho$ subunit-containing GABA receptors as the mediators of this action of GABA. Figure 5 shows that the superfusion of guinea pig retinal slice with the $\rho$-subunit-containing GABA receptor antagonist TPMPA increased the cone Ca channel current amplitude. This was accompanied by a negative shift of the $\mathrm{Ca}_{\mathrm{V}}$ channel activation curve with $\mathrm{V}_{\frac{1}{2}}$ decreasing by about $10 \mathrm{mV}$. TPMPA had a similar action on mouse cones, shifting the activation curve negative by about $6 \mathrm{mV}$. Neither gabazine nor strychnine produced activation curve shifts in rodents.

Similar to the effects of picrotoxin discussed in Figure 4, TPMPA, gabazine, and strychnine did not produce conductance decreases in cones between -90 and $-60 \mathrm{mV}$, a zone well away from the $\mathrm{Ca}_{V}$ channel activation range, suggesting that GABARs are not functional in cones under the recording conditions used here.

\section{WHERE ARE THESE $\rho$-SUBUNIT-CONTAINING GABARs LOCATED?}

The pharmacological results in Figure 5 indicated a role for GABA receptors containing $\rho$-subunits in feedback. $\rho$-subunitcontaining GABA receptors are not found in mammalian cones but these GABARs have been identified in horizontal cells with GABA-mediated responses reported in fish, salamander, rat, guinea pig, and mouse horizontal cells ( $\mathrm{Wu}$ and Dowling, 1980; Kamermans and Werblin, 1992; Dong et al., 1994; Takahashi et al., 1995; Verweij et al., 1998; Yang et al., 1999; Bormann, 2000; Feigenspan and Weiler, 2004; Liu et al., 2013; Grove et al., 2019).

Concerning data supporting a role for this subset of GABARs in modulating cone $\mathrm{Ca}_{\mathrm{V}}$ channels, using immunohistochemical approaches, Grove et al. (2019) showed that antibodies against $\rho$-subunit-containing GABARs are expressed not in cones but rather in horizontal cells, and specifically in the cells' synaptic endings where they would be localized close to the synaptic cleft (Figure 6). Super-resolution confocal images of retinal sections indicated co-localization of GABAR $\rho 2$ subunits (and $\rho 1$ subunits, not shown) with the horizontal cell marker calbindin in horizontal cell processes at synapses with both rods and cones(Grove et al., 2019). The structures show elements typical of electron microscopic images of horizontal cell invagination of photoreceptors and no evidence for $\rho$-subunit-containing GABARs in rods and cones. GABARs containing $\rho$-subunits have a high affinity for GABA and are non-desensitizing (Farrant and Kaila, 2007), consistent reports of a GABA-activated conductance in mammalian horizontal cells (Feigenspan and Weiler, 2004; Liu et al., 2013). The GABARs recently found in mouse cones (Deniz et al., 2019) do not include the $\rho$ subunitcontaining type shown here. 

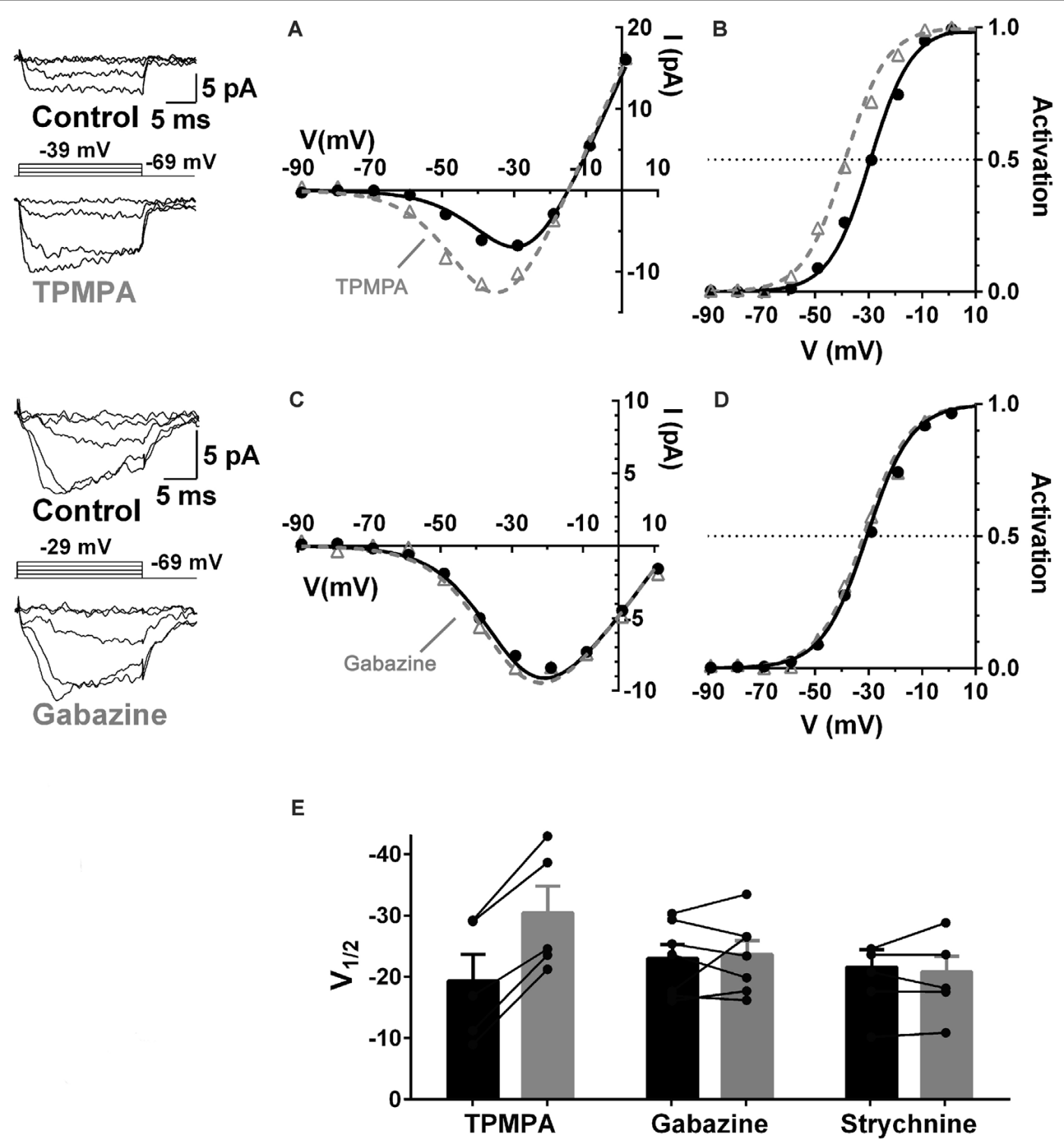

FIGURE 5 | GABA receptors containing $\rho$-subunits mediate the modulation of cone Cav currents. Effects of GABAR blockers on Ca channel currents in cones in guinea pig retinal slices. (A,B) The $\rho$-subunit-containing GABAR antagonist TPMPA (50 $\mu$ M) shifted Cav activation in guinea pig cones to more negative voltages, in this case by $10 \mathrm{mV}$. (C,D) The GABA $\mathrm{R}$ antagonist gabazine $(10 \mu \mathrm{M})$ did not affect Cav activation. (E) Summary of the effects of TPMPA, gabazine, and the GlyR antagonist strychnine $(100 \mu \mathrm{M})$ on Cav channel activation (5-7 cones). In each pair the filled bar (on left) is control and the gray bar (on right) shows the change in the presence of the blocker. Figure modified from Grove et al. (2019).

\section{THE CELLS THAT RELEASE THE GABA RESPOND TO IT: AN AUTAPTIC MECHANISM}

When currents in voltage-clamped horizontal cells, identified by their fluorescence in the Cx57-tdTomato mouse line (Hirano et al., 2016), were compared before and during the superfusion of TPMPA, the $\rho$-subunit-containing GABAR antagonist, a voltage-independent current reversing near the $\mathrm{Cl}^{-}$equilibrium potential, was the only difference (Figure 7 ). The I-V relation obtained by subtracting the currents measured in TPMPA from those in control isolates the TPMPA-sensitive current, with a reversal potential near $-70 \mathrm{mV}$. The recordings had to be performed in the presence of CNQX and Hepes to eliminate input from cones and possible effects of feedback. This mostly linear current component (notwithstanding the "bump" at -40 and $-30 \mathrm{mV}$ ), being the current blocked by TPMPA, is by definition a $\rho$-subunit-containing GABAR current, revealed a tonic GABA-activated $\mathrm{Cl}^{-}$current in the mouse horizontal cell.

The existence of a tonic GABA-activated current, that can be blocked with TPMPA over a broad range of potentials suggests that under the recording conditions used, GABA is tonically 

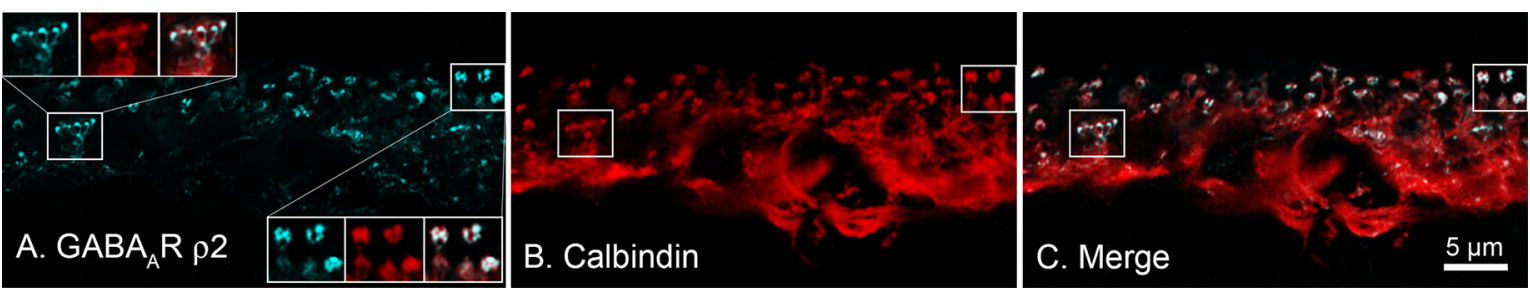

FIGURE 6 | Horizontal cells express $\rho$-subunit-containing GABA receptors in their synaptic endings in the mouse retina. (A) Immunolocalization of the $\rho 2$ subunit (blue). (B) Horizontal cell marker, calbindin immunoreactivity (red). (C) Merged image shows that expression of $\rho 2$ subunits is limited to the tips of horizontal cell synaptic endings that invaginate rod and cone photoreceptor terminals (Insets show magnified images in Panel (A), upper left, of a single cone pedicle; lower right, 3-rod spherules). Figure modified from Grove et al. (2019).

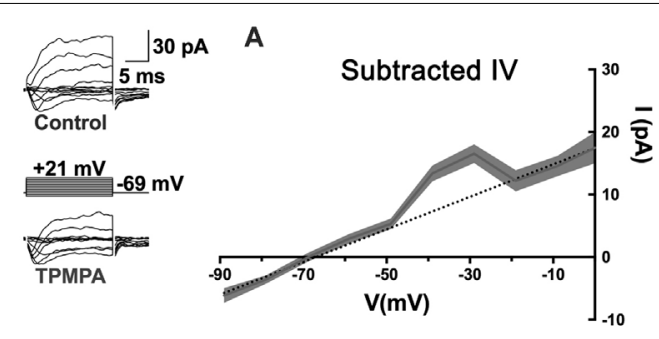

D

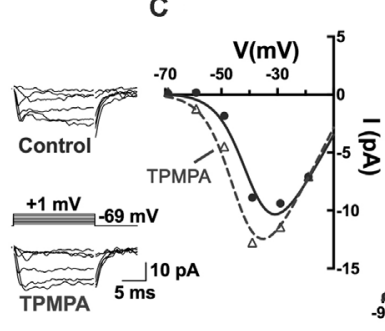

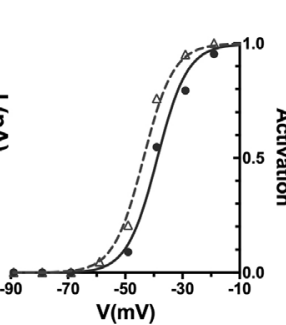
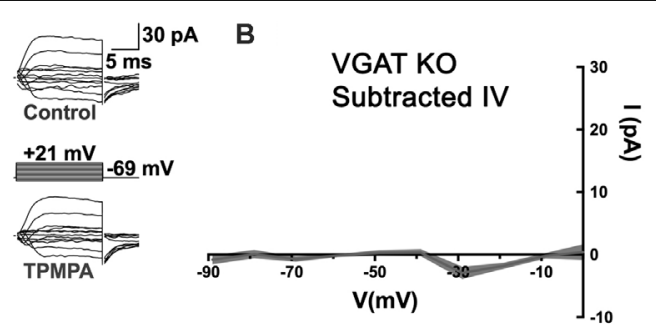

E

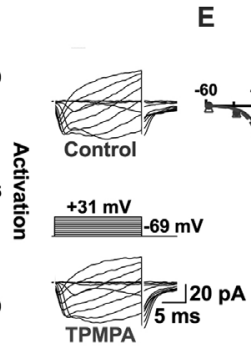

E

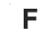

$\mathbf{F}$

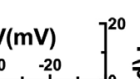

VGAT KO

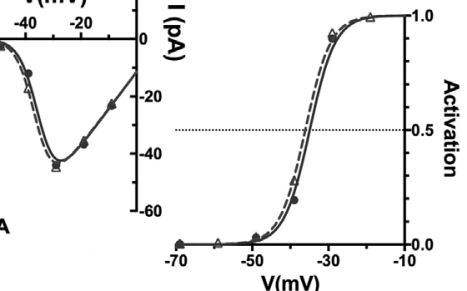

FIGURE 7 | An autaptic mechanism: horizontal cells release GABA and respond to it via $\rho$-subunit-containing GABARs, and feedback to cones depends upon it. (A) Patch-clamp recording of Cx57-tdTomato labeled mouse horizontal cells in a slice bathed in CNQX (50 $\mu \mathrm{M}$ ) and Hepes buffer (10 mM, pH 7.4) to isolate it from feedback and cone input. Whole-cell currents were elicited in horizontal cells with voltage steps, in control and in TPMPA (50 $\mu \mathrm{M})$. Averaged I-V relations of steady-state TPMPA-subtracted currents showed a linear component reversing near $-70 \mathrm{mV}$. Linear fitting excluded values near -40 and $-30 \mathrm{mV}$. Gray shading shows the standard deviation of 5 horizontal cell recordings. (B) Same experiment and protocol as in panel (A) but recorded from Cx57-VGAT KO mouse horizontal cells that lack VGAT, which have synaptic vesicles devoid of GABA (Hirano et al., 2016). The mouse horizontal cells lacking VGAT were unaffected by TPMPA, suggesting that the tonic GABA levels in the wild-type are due to horizontal cell release and autaptic reception. (C) Recording of cone Cav channel currents in a wild-type mouse, showing current in control and in presence of TPMPA, with I-V relations. (D) Activation curves showed that the Cav channel activation midpoint shifted negative by about $5 \mathrm{mV}$ in presence of TPMPA. Same experimental protocol as in panel (C) but in a Cx57-VGAT KO mouse cone, showing that the I-V relations $(\mathbf{E})$ and the activation midpoints $\mathbf{( F )}$ were unaffected by TPMPA in cones when horizontal cells were unable to release GABA. Figure modified from Grove et al. (2019).

present in the synaptic cleft. This could arise from GABA being tonically released, even from modestly hyperpolarized horizontal cells, released from other GABAergic cells, or not being effectively removed from the synaptic cleft. As stated earlier, mammalian horizontal cells do not express GABA-uptake transporters, so there appears to be no localized removal mechanism in the protected synaptic cleft other than diffusion from the invagination followed by uptake by Müller cells (Bringmann et al., 2013). To test whether the tonic presence of GABA in the synaptic cleft is a result of horizontal cell release, horizontal cells incapable of expressing the vesicular GABA transporter, VGAT, were recorded from in Cx57-VGAT-KO mouse retinas (Hirano et al., 2016). In horizontal cells of this mouse line, the only retinal cell type expressing Cx57, the GABA transporter that loads synaptic vesicles with GABA is selectively deleted, rendering them incapable of releasing GABA. Matching the recording protocol used in Figure 7A but recording in VGAT-KO animals, TPMPA no longer caused any change in horizontal cell currents (Figure 7B). Horizontal cells in VGAT-KO mice exhibited normal expression of $\rho$-subunit containing GABARs in horizontal cells, so the fact that in the Cx57-VGAT-KO mice there was no TPMPA-sensitive current to be blocked means that in the control retinas, the horizontal cells respond autaptically to the GABA they release. 
Returning to the outward current bump between -40 and $-30 \mathrm{mV}$ in Figure 7A, it is difficult to identify the source of this but it is possible since this is the range of voltages that peak $\mathrm{Ca}_{\mathrm{V}}$ channel activation occurs in horizontal cells (Liu et al., 2016), that the bump reflects TPMPA block of extra GABAR $\mathrm{Cl}^{-}$current arising from increased GABA release at those potentials. An increase of the horizontal cell $\mathrm{Ca}_{\mathrm{V}}$ current due to alkalinization in the synaptic cleft, similar to that seen in cone $\mathrm{Ca}_{V}$ current when TPMPA is added (Figure 7C), could induce additional GABA release by the horizontal cell.

\section{THE TONIC, AUTAPTIC GABAR CURRENT IN HORIZONTAL CELLS IS REQUIRED FOR FEEDBACK TO CONES}

Do the actions of TPMPA on cone $\mathrm{Ca}_{V}$ channels depend on the release of GABA from horizontal cells, which are the same cells that respond to it? Using the same Cx57-VGAT KO mice in which horizontal cell GABA release was eliminated, it was shown that the cone $\mathrm{Ca}_{\mathrm{V}}$ currents, that underwent negative shifts in their activation midpoint in response to TPMPA in wild-type mice (Figures 7C,D), showed no change in their $\mathrm{Ca}_{V}$ channel activation in Cx57-VGAT-KO mice (Figures 7E,F). Since there is no evidence that there are functional $\rho$-subunit containing GABARs in cones or that those GABARs directly modulate $\mathrm{Ca}_{\mathrm{V}}$ channel gating, the observed $\mathrm{Ca}_{V}$ channel activation curve shifts in cones were interpreted to be caused by GABA, released by horizontal cells and acting locally on horizontal cells via TPMPAsensitive GABARs. However, this means that an additional "messenger" appears required to carry the signal from horizontal cells to the cone membrane where it affects cone $\mathrm{Ca}_{\mathrm{V}}$ currents.

\section{THE EFFECTS OF pH AND GABA MERGE THROUGH A CONCERTED BIOPHYSICAL MECHANISM}

The anion pore of GABA-activated channels is $20-60 \%$ as permeable to $\mathrm{HCO}_{3}^{-}$as it is to $\mathrm{Cl}^{-}$(Bormann et al., 1987; Kaila and Voipio, 1987; Fatima-Shad and Barry, 1993; Hubner and Holthoff, 2013). A $\mathrm{P}_{\mathrm{HCO} 3} / \mathrm{P}_{\mathrm{Cl}}$ of 0.29 was measured in rat horizontal cell GABAR channels (Liu et al., 2013). With internal and external $\mathrm{HCO}_{3}^{-}$concentrations both being in the $10-25 \mathrm{mM}$ range, the considerable flux of this ion through GABAR channels has been shown to change extracellular $\mathrm{pH}$ in many brain areas (Bormann et al., 1987; Kaila and Voipio, 1987). This is how the $\mathrm{pH}$ sensitivity of the cone $\mathrm{Ca}_{\mathrm{V}}$ channel activation is linked to GABA, being mediated by the flux of the two common permeant anions of GABA-activated channels, $\mathrm{Cl}^{-}$, and $\mathrm{HCO}_{3}^{-}$, across the horizontal cell membrane in accounting for GABA-mediated inhibition and disinhibition of cone $\mathrm{Ca}_{\mathrm{V}}$ channels, in the GABA-pH model (Liu et al., 2013; Grove et al., 2019).

The foundation of the GABA-pH hybrid model includes the following concerted biophysical mechanisms: (1) GABA acting on horizontal cell GABARs autaptically and tonically (Gilbertson et al., 1991; Kamermans and Werblin, 1992; Feigenspan and Weiler, 2004; Liu et al., 2013; Grove et al., 2019); (2) these
GABARs mediating the efflux of the permeant anion $\mathrm{HCO}_{3}^{-}$; and (3) the subsequent buffering of cleft $\mathrm{pH}$, modulating photoreceptor transmitter release via surface charge effects on presynaptic cone $\mathrm{Ca}_{\mathrm{V}}$ channels (Barnes et al., 1993; Vessey et al., 2005; Cadetti and Thoreson, 2006; Grove et al., 2019). The sign and magnitude of the contribution of the GABAR channel to cleft $\mathrm{pH}$ depend on the driving force on $\mathrm{HCO}_{3}^{-}$, which is itself a $\mathrm{pH}$-dependent function of the equilibrium potential for $\mathrm{HCO}_{3}^{-}\left(\mathrm{E}_{\mathrm{HCO}}^{-}\right)$, a value typically in the range of -10 to $-20 \mathrm{mV}$ (Roos and Boron, 1981), and the horizontal cell membrane potential.

Together, these concerted factors imply that, given a tonic presence of GABA in the synaptic cleft, disinhibition of cone $\mathrm{Ca}_{V}$ channels would be greatest when horizontal cell membrane potentials were most negative, thus producing more $\mathrm{HCO}_{3}^{-}$ efflux due to the strengthened driving force. Whether reduced $\mathrm{HCO}_{3}^{-}$efflux at more positive horizontal cell voltages would be able to do the opposite, i.e., permit inhibition of photoreceptor $\mathrm{Ca}_{V}$ channels, due to the reduced alkalinizing influence, and otherwise allow acidifying influences to dominate, are questions addressed in the final section of this review.

\section{HORIZONTAL CELL DEPOLARIZATION INHIBITS PHOTORECEPTORS}

While $\mathrm{HCO}_{3}^{-}$efflux from horizontal cells during hyperpolarization accounts for the disinhibition of photoreceptor $\mathrm{Ca}_{V}$ channels caused by increased alkalinity, do horizontal cell depolarization produce inward flux of $\mathrm{HCO}_{3}^{-}$or reduce the outward driving force on $\mathrm{HCO}_{3}^{-}$efflux sufficiently to account for the inhibition of photoreceptor $\mathrm{Ca}_{V}$ channels? The outward rectification provided by $\mathrm{BK}$ channels (Sun et al., 2017), which activate steeply positive to $-30 \mathrm{mV}$, prevents horizontal cell depolarization positive to $\mathrm{E}_{\mathrm{HCO} 3}^{-}$, a value typically in the range of -15 to $-20 \mathrm{mV}$ for cells (Bolton and Vaughan-Jones, 1977). This means that an inward flux of bicarbonate would not occur under normal physiological conditions. But the reduced outward driving force on $\mathrm{HCO}_{3}^{-}$when the horizontal cell is depolarized, as occurs maximally in the dark, would lead to less $\mathrm{pH}$ buffering of the synaptic cleft and set the stage for acidifying influences to play an inhibitory role. What are those acidifying influences and how does activation of GABARs enhance this process?

First, the activation of GABARs themselves contributes to the depolarization of horizontal cells. The GABAR agonist muscimol elicited currents reversing near $-28 \mathrm{mV}$ during recordings in mouse horizontal cells made with the gramicidin perforated patch technique, which preserves physiological intracellular chloride levels (Figure 8; Grove et al., 2019). This reversal potential of GABAR-activated currents suggested that $\mathrm{E}_{\mathrm{Cl}}$ of the horizontal cell is much more positive than is typical for mature neurons, and has been previously observed for horizontal cells (Miller and Dacheux, 1983; Djamgoz and Laming, 1987; Kamermans and Werblin, 1992). Current-clamp recordings confirm that depolarization caused by GABAR activation contributes to positive membrane 


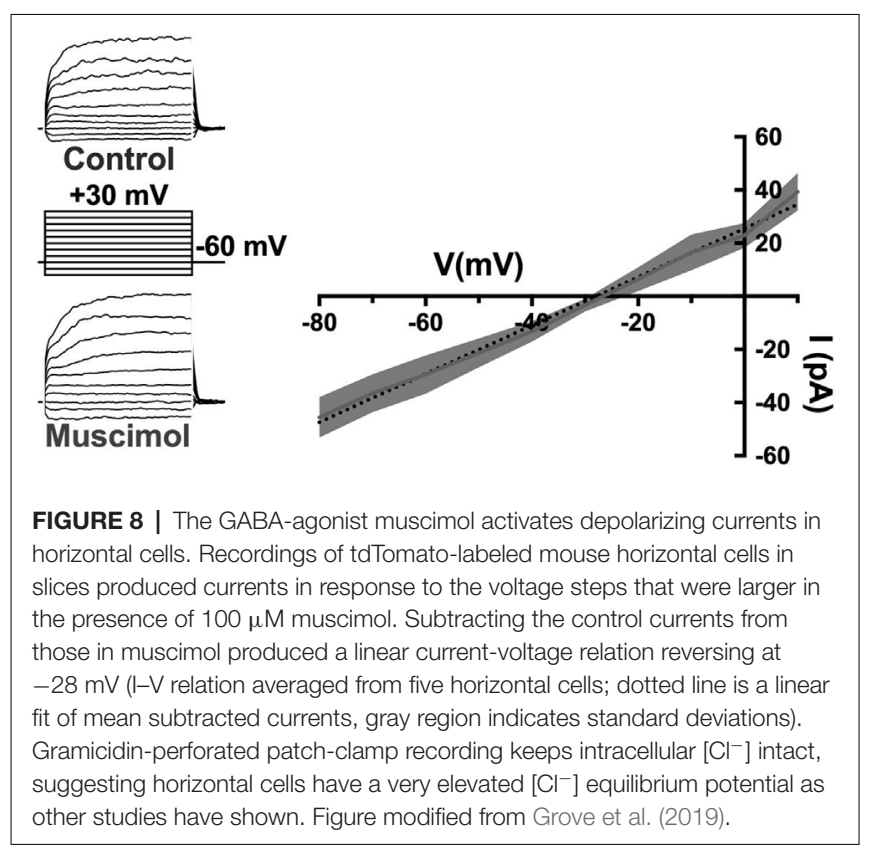

potentials in horizontal cells (Grove et al., 2019). Thus, GABAR activation depolarizes these cells, decreasing $\mathrm{HCO}_{3}^{-}$efflux, and this action could increase the acidifying influences on cleft $\mathrm{pH}$.

Relatively positive equilibrium potential for $\mathrm{Cl}^{-}$is produced in neurons by $\mathrm{Na}^{+} / \mathrm{K}^{+} / \mathrm{Cl}^{-}$cotransporters (NKCC), that move $\mathrm{Cl}^{-}$into cells electroneutrally using the $\mathrm{Na}^{+}$and $\mathrm{K}^{+}$ gradients (Russell, 2000; Achilles et al., 2007). A specific subtype, NKCC1 (Slc12a2), has been previously identified in mammalian horizontal cells (Vardi et al., 2000) and would make any chloride conductance have a depolarizing effect. This depolarizing action of muscimol in horizontal cells (Figure 8) was shown to be due to a $7 \mathrm{mV}$ positive shift of the $\mathrm{Ca}_{V}$ current activation curve (Figure 9; Grove et al., 2019). This outcome is consistent with the negative shifts of the cone $\mathrm{Ca}_{\mathrm{V}}$ current activation curve produced by GABAR antagonists in Figures 4, 5, 7. When NKCC1 was blocked with bumetanide (Morita et al., 1999), the sign of muscimol's cone $\mathrm{Ca}$ channel modulation was changed from inhibition to disinhibition. In the presence of bumetanide $\left(\begin{array}{ll}50 & \mu \mathrm{M}\end{array}\right)$, muscimol shifted the $\mathrm{Ca}_{\mathrm{V}}$ current activation curve midpoint slightly negative (about $2 \mathrm{mV}$ ). This modest disinhibitory action induced by bumetanide could follow from the block of NKCC1 in horizontal cells, which would reduce intracellular $\left[\mathrm{Cl}^{-}\right]$to sufficiently low levels that GABAR activation no longer depolarizes them and might even produce hyperpolarization.

The disinhibitory action that followed the block of the inward $\mathrm{Cl}^{-}$transporter in horizontal cells suggests that the removal of the depolarizing influence of GABA allowed other actions, such as increased $\mathrm{HCO}_{3}^{-}$efflux, to become dominant and alkalinize the synaptic cleft, leading to the $\mathrm{pH}$-dependent disinhibition of cone $\mathrm{Ca}_{V}$ channels. With tonic, the autaptic release of GABA by horizontal cells appearing to inhibit cone $\mathrm{CaV}_{\mathrm{V}}$ channels in a manner due in part to its depolarizing effect on horizontal cells, the question remaining was what other cleft acidifying processes are initiated or increased when horizontal cells depolarize.

\section{BLOCK OF NHES PRODUCES CLEFT ALKALINIZATION UNDERLYING DISINHIBITION OF CONE Cav CHANNELS}

NHEs were implicated in feedback inhibition of photoreceptors in non-mammalian vertebrates (Warren et al., 2016a). This acid extruder is electroneutral, meaning that it has no intrinsic voltage sensitivity and is not affected by membrane potential directly. However, NHEs are more active when neurons are depolarized due to their increased ion channel activity and the metabolic activity associated with ion pumping to restore gradients. Concomitant with this major influence, NHEs are sensitive to intracellular $\mathrm{pH}\left(\mathrm{pH}_{\mathrm{i}}\right)$ and internal calcium levels and both of these stimuli increase with depolarization (Aronson et al., 1982; Madshus, 1988; Bertrand et al., 1994; Ma and Haddad, 1997; Koster et al., 2011). Increased NHE activity in mammalian horizontal cells is associated with horizontal cell modulation of cone $\mathrm{Ca}_{V}$ channels (Warren et al., 2016a; Grove et al., 2019). Using the same mesopic light-adapted retinal slices, the selective NHE blocker cariporide $(10 \mu \mathrm{M})$, by itself, shifted mouse cone $\mathrm{Ca}_{v}$ channel activation curves negative by about $6 \mathrm{mV}$, disinhibition consistent with the block of NHEs that had had an acidifying effect on the synaptic cleft (Figures 10A,B). The sign and magnitude of this effect are close to that seen in Figures 4, 5 where the GABAR antagonist TPMPA was used by itself. Figures 10C,D show that the addition of TPMPA $(50 \mu \mathrm{M})$ to the cariporide treated slice produced no shift of the $\mathrm{CaV}_{\mathrm{V}}$ channel activation curve. Nearly identical results were reported using another blocker of NHEs, amiloride $(30 \mu \mathrm{M})$, suggesting that the inhibitory effects of GABARs on cone $\mathrm{Ca}_{V}$ channel activation is due to conditions that NHE activity produced (Grove et al., 2019).

Figure 1 confirms that cone $\mathrm{Ca}_{V}$ channels are inhibited under steady-state mesopic conditions due to elevated NHE activity. The Block of NHEs leads to alkalinization of cleft $\mathrm{pH}$, altering $\mathrm{Ca}_{V}$ channel gating like GABAR block with picrotoxin and TPMPA, shown in Figures 4, 5. However, an earlier report showed that GABA increased rat photoreceptor $\mathrm{Ca}_{V}$ currents under bright light, conditions under which horizontal cell membrane potential would be very negative (Liu et al., 2016), suggesting that GABA may therefore have alkalinizing effects when horizontal cells are hyperpolarized.

\section{GABARs AND THE HORIZONTAL CELL MEMBRANE POTENTIAL: INHIBITION WITH DEPOLARIZATION, DISINHIBITION WITH HYPERPOLARIZATION}

The polarity of cone $\mathrm{Ca}_{V}$ channel modulation depends on the horizontal cell membrane potential.

Recordings of the modulation of $\mathrm{Ca}_{V}$ channels in cones from retinas adapted to mesopic illumination and maintained 

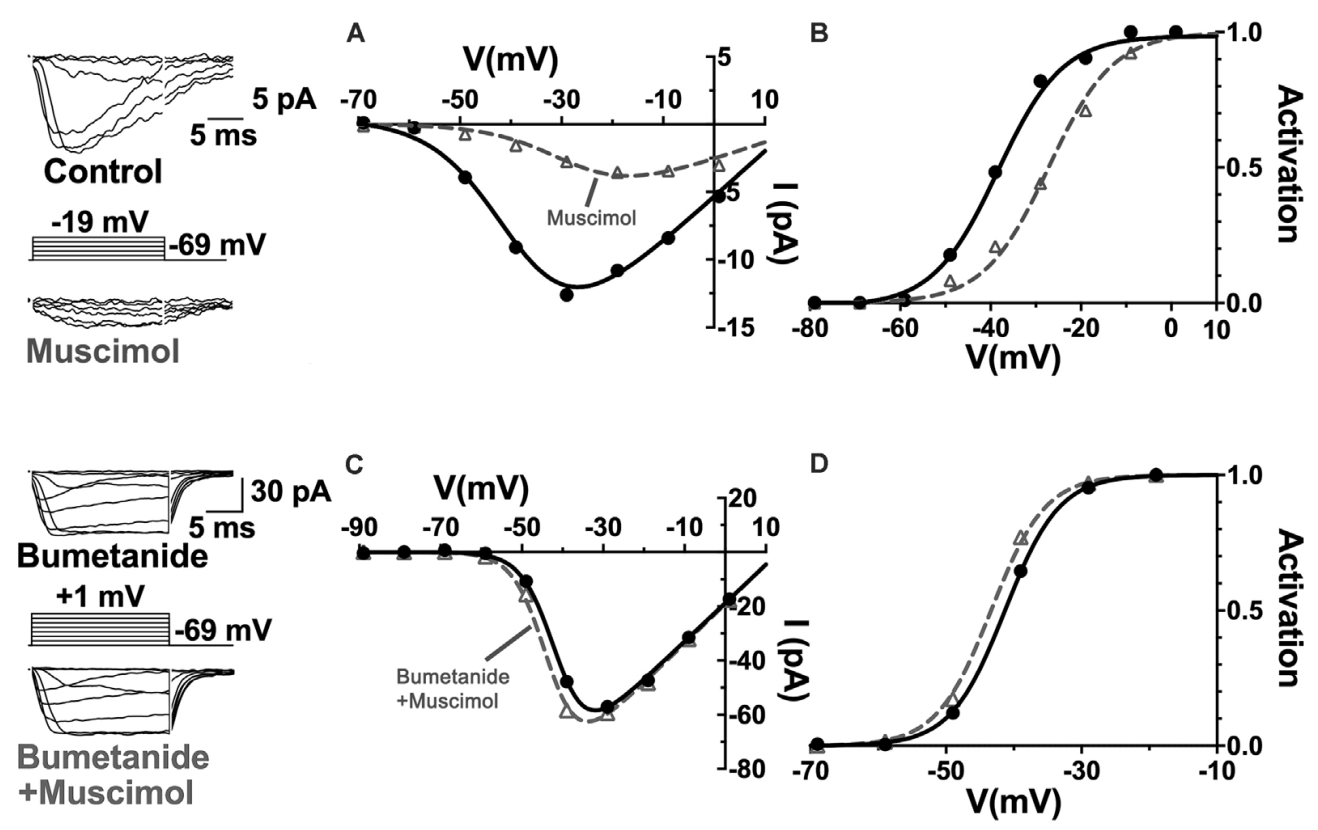

FIGURE 9 | The NKCC blocker bumetanide eliminates the muscimol-induced activation curve shift of cone Cav channels. (A) I-V relations with smaller Cav channel currents were produced in the presence of muscimol, which is accounted for by the strong rightward shift of the Cav channel activation curve midpoint (B). (C) Same experimental paradigm as above but slices superfused with bumetanide for 30 min. Cav channel currents in the absence and presence of muscimol produced I-V relations and activation curves having only a slight leftward activation midpoint shift with muscimol in bumetanide-treated retinas (D). Figure modified from Grove et al. (2019).

in low light conditions showed that horizontal cells were in a relatively depolarized state (Grove et al., 2019). This is a well-known consequence of the release of glutamate by photoreceptors in low light. Horizontal cells are depolarized by glutamate, which is released in a graded manner by photoreceptors maximally in darkness. Horizontal cells rest under this condition at membrane potentials as high as $-30 \mathrm{mV}$. It is broadly appreciated that reducing glutamatergic transmission with intense illumination or with glutamate receptor antagonists, horizontal cells hyperpolarize to levels near $-60 \mathrm{mV}$ (Hirasawa and Kaneko, 2003). When they are depolarized, horizontal cells inhibit photoreceptor $\mathrm{Ca}_{V}$ channels, and when they are hyperpolarized, they produce disinhibition of those channels (Thoreson et al., 2008). During recordings from cones in low light conditions with mesopic adaptation, as seen in Figures 9, 11A,B, muscimol (100 $\mu \mathrm{M})$ application produced inhibition, a $6 \mathrm{mV}$ rightward shift of the $\mathrm{Ca}_{V}$ channel activation curve (Grove et al., 2019). When retinas were superfused with CNQX $(50 \mu \mathrm{M})$, which shifted cone $\mathrm{Ca}_{\mathrm{V}}$ activation leftward $6 \mathrm{mV}$ by itself, the effect of added muscimol application produced an $11 \mathrm{mV}$ leftward shift in the cone $\mathrm{Ca}_{V}$ channel activation midpoint, a strong disinhibitory influence on the cone (Figures 11C,D). This result, summarized in Figure 11E, confirms earlier reports that photoreceptor $\mathrm{Ca}_{\mathrm{V}}$ channel activation depends directly on horizontal cell membrane potential (Hirasawa and Kaneko, 2003; Cadetti and Thoreson, 2006; Babai and Thoreson, 2009; Grove et al., 2019), and that GABAR-mediated cone inhibition and disinhibition are functions of the horizontal cell membrane potential (Liu et al., 2013). This implies that the sign of GABA's tonic influence on feedback depends on the immediate (light-dependent) polarization of the horizontal cell membrane potential.

NHEs never mediate $\mathrm{H}^{+}$influx (Löscher et al., 2013) and therefore do not account for alkalization of the synaptic cleft in a hyperpolarized horizontal cell treated with CNQX. The $\mathrm{Ca}_{\mathrm{V}}$ current disinhibition in cones seen in CNQX is due to horizontal cell GABAR-mediated $\mathrm{HCO}_{3}^{-}$efflux, which increases with horizontal cell hyperpolarization. GABAR activation with muscimol also failed to inhibit cone $\mathrm{Ca}_{\mathrm{V}}$ channels in the presence of the NKCC1 blocker bumetanide and the NHE blockers amiloride and cariporide. These individual component effects support the conclusion that GABARmediated inhibition of cone $\mathrm{Ca}_{V}$ channels depends on horizontal cell depolarization and that this is outweighed by disinhibitory actions during hyperpolarization.

\section{DISCUSSION AND CONCLUSIONS}

This review integrates the guiding concepts about feedback that have emerged over the past half-century with findings from a recent report to describe a novel solution for how synaptic feedback occurs in mammalian retinas. To aid the comparison of this new GABA-pH hybrid model with earlier reports, Figure 12 summarizes the key membrane properties of photoreceptors and horizontal cells at the synaptic cleft that are central to the model. The central foundational tenet of the feedback mechanism is well-established in mammalian 

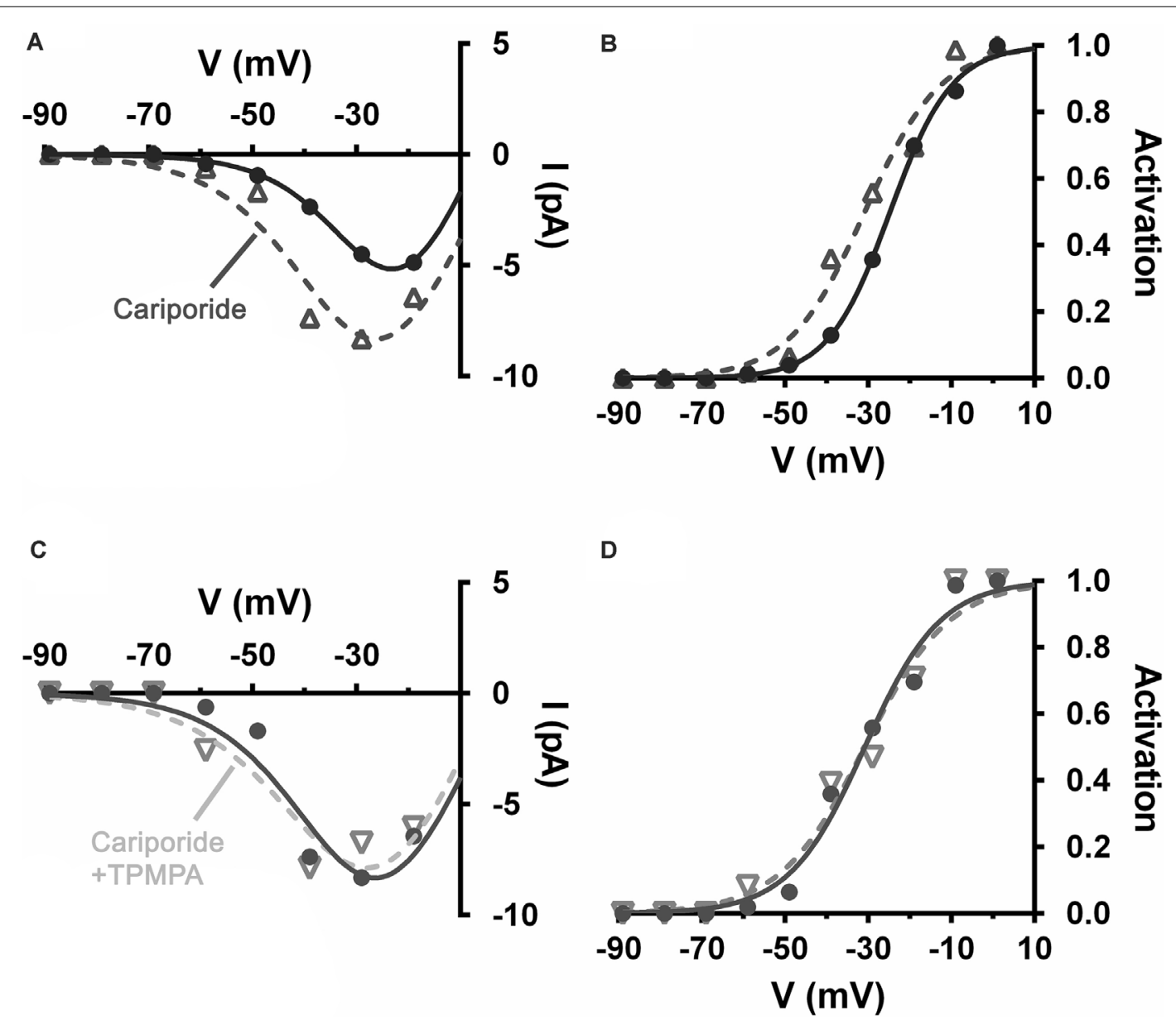

FIGURE 10 | Alkalinization of the extracellular space produced by blocking $\mathrm{Na}^{+} / \mathrm{H}^{+}$exchangers (NHEs), disinhibited cone Cav and occluded disinhibition by TPMPA. Recording of Cav currents in a mouse cone. (A) I-V relations show larger currents in the presence of cariporide (dashed line, open triangles) relative to control (solid line, filled circles). (B) The cone Cav activation curve shifts to a more negative potential following cariporide application (dashed line, open triangles). (C) In the same mouse cone bathed continuously with cariporide, I-V relations showed no effect of TPMPA on Cav current (dashed line, inverted triangles). (D) TPMPA failed to shift the Cav activation curve to more negative potentials (dashed line, inverted triangles).

and non-mammalian vertebrates, namely, that horizontal cell depolarization inhibits photoreceptor voltage-gated $\mathrm{Ca}_{V}$ channels (Verweij et al., 1996). Two mechanisms for this channel modulation have been proposed, and both likely apply broadly, albeit with varying impacts upon the feedback process in different species. First, as described above, the electric feedback model (Byzov and Shura-Bura, 1986) and the hemichannelmediated ephaptic coupling (Kamermans et al., 2001) posit that extracellular current flow into the synaptic invagination, terminating at the glutamate receptors and/or hemichannels at the tips of horizontal cell processes, changes the extracellular voltage, and this alters the photoreceptor $\mathrm{Ca}_{V}$ channel activation by changing the membrane electric field that governs channel gating. While compelling evidence for these actions comes from investigations in fish, none is available for connexion hemichannels at mammalian horizontal cell synaptic tips. Second, a host of reports show that feedback from horizontal cells is mediated by $\mathrm{pH}$ shifts within the synaptic cleft (Hirasawa and
Kaneko, 2003; Vessey et al., 2005; Cadetti and Thoreson, 2006; Wang et al., 2014). Before this recent report (Grove et al., 2019), no convincing model of what drives the $\mathrm{pH}$ shifts as a function of horizontal cell membrane potential has emerged in mammals. The role of pannexin hemichannels in changing $\mathrm{pH}_{\mathrm{o}}$ has been supported in zebrafish and invokes the efflux of ATP from horizontal cells through hemichannels followed by hydrolytic generation of phosphates capable of buffering $\mathrm{pH}$ (Vroman et al., 2014). The presence of pannexins is supported in fish (Cenedese et al., 2017), but the evidence does not support their appropriate localization in mammalian horizontal cells (Kranz et al., 2013). Although not considered a component of inhibitory feedback, the effect on $\mathrm{Ca}_{\mathrm{V}}$ channel activation of a sudden $\mathrm{pH}$ reduction in the synaptic cleft was described during fast depolarizationinduced vesicle fusion in photoreceptors, where the acidic vesicle contents are released to produce rapid and transient inhibition of the $\mathrm{Ca}_{\mathrm{V}}$ channels responsible for the vesicle fusion (DeVries, 2001). Such an action, essentially due to a quick infusion of a 


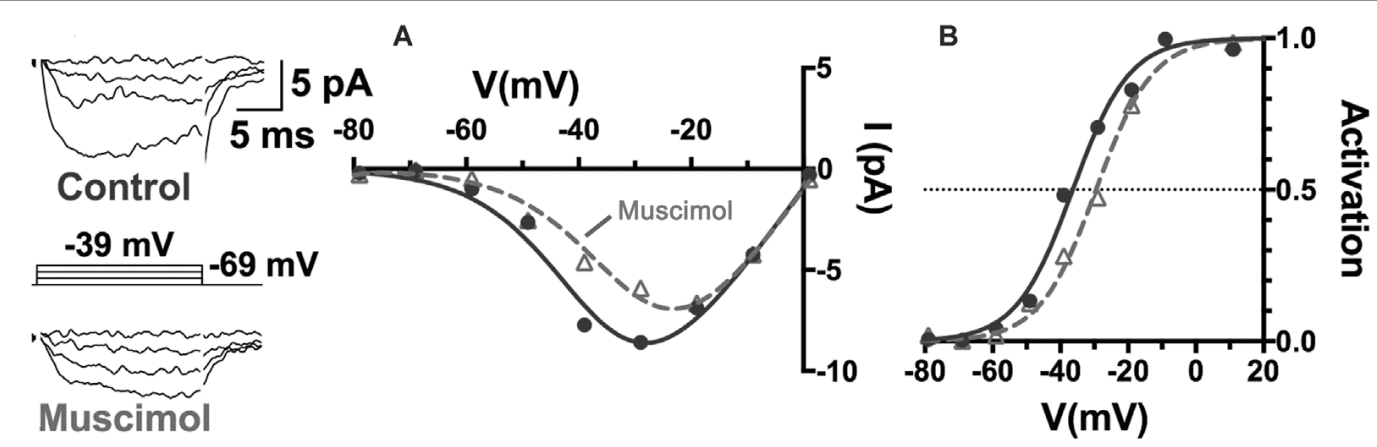

C
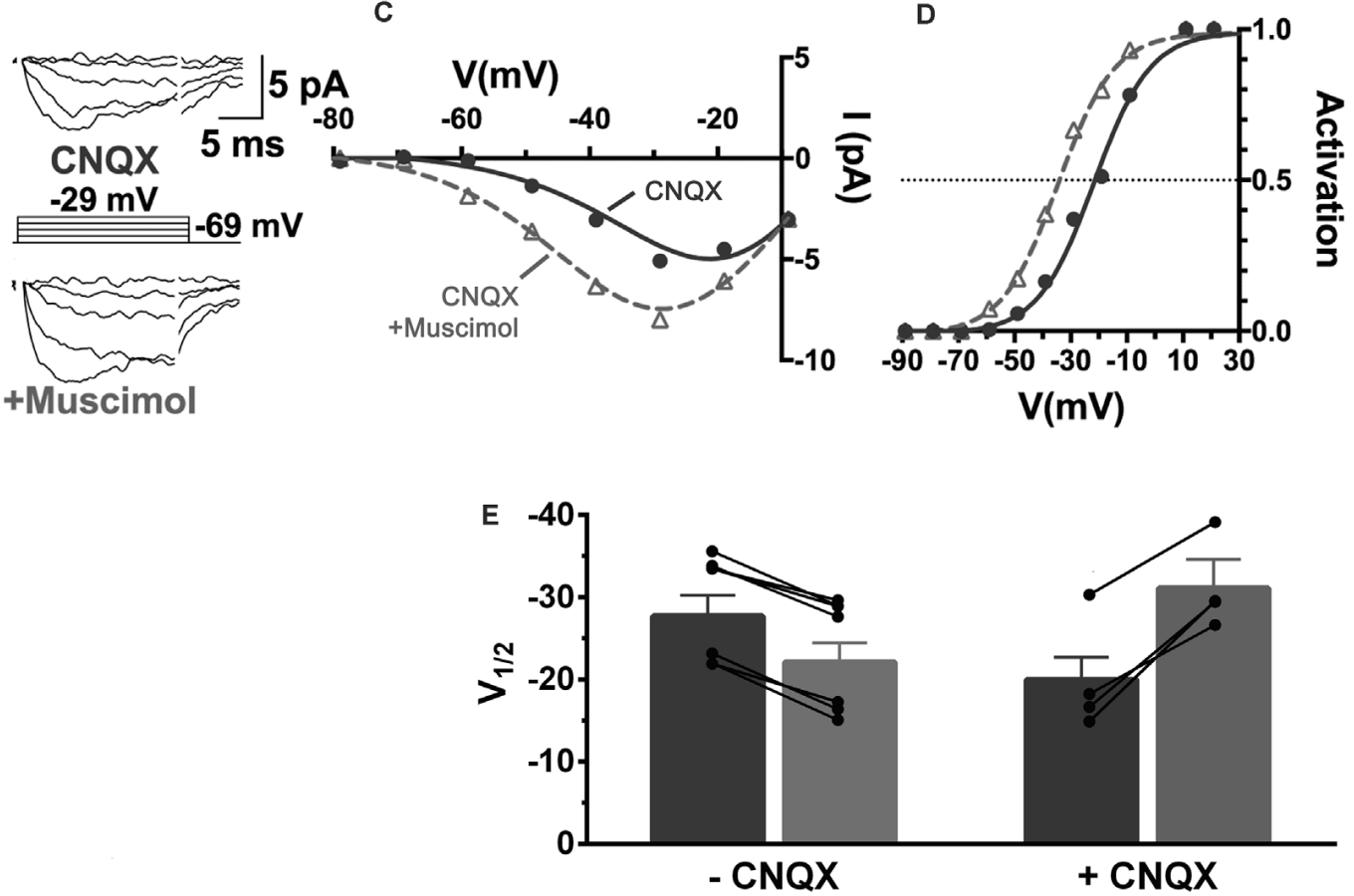

FIGURE 11 | The sign of GABA's influence on feedback is dependent on the horizontal cell membrane potential. Cav currents in cones are inhibited or disinhibited by muscimol depending on whether CNQX is present to block glutamatergic input to horizontal cells. (A) I-V relations show smaller cone Cav currents during muscimol superfusion in the absence of CNQX, due to Cav channel activation curve shifting $7 \mathrm{mV}$ positive (B) during muscimol application. (C) In the presence of CNQX, which hyperpolarizes cones, muscimol shifted activation curve $V_{\frac{1}{2}}$ to a more negative voltage (D), leading to larger currents at all membrane potentials. (E) Changes to cone Cav channel activation curve midpoint caused by muscimol with or without the presence of CNQX show that the effect of muscimol depends on horizontal cell membrane potential as controlled by glutamate. Figure modified from Grove et al. (2019).

bolus of protons, is fundamentally different than the continuous flow of protons via NHEs, or the continuously modulated efflux of the buffer $\mathrm{HCO}_{3}^{-}$described in this report.

Another mechanism involving the efflux of a $\mathrm{pH}$ buffer from horizontal cells, the GABA-pH model reviewed here in the mammalian retina, is more complex and implicates GABA in mediating the $\mathrm{pH}$ shifts. GABA that activates $\mathrm{C1}^{-}$ and $\mathrm{HCO}_{3}^{-}$permeable GABAR autoreceptors are released tonically (Gilbertson et al., 1991; Kamermans and Werblin, 1992; Feigenspan and Weiler, 2004; Liu et al., 2013). In keeping with the tenet of feedback, i.e., that it is driven by the membrane potential of the horizontal cell, hyperpolarization is responsible for the tonic GABAR-mediated $\mathrm{HCO}_{3}^{-}$efflux that alkalinizes the synaptic cleft. It depends on the driving force on $\mathrm{HCO}_{3}^{-}$, which is a function of the equilibrium potential for $\mathrm{HCO}_{3}^{-}$ $\left(\mathrm{E}_{\mathrm{HCO}_{3}}\right.$; typically in the range of -15 to $-20 \mathrm{mV}$ ) and the membrane potential of horizontal cells. This means that cone $\mathrm{Ca}_{V}$ channel disinhibition is greatest in the most negative range of horizontal cell membrane potentials, such as during stimulation with bright light. In contrast, the $-30 \mathrm{mV}$ reversal potential of GABAR can add to depolarization of the cell in a manner that increases cleft acidification, which is amplified by the non-linear $\mathrm{H}^{+}$efflux via NHEs responding to intracellular metabolically driven acidification.

The results reported in Grove et al. (2019) and reviewed here are consistent with some features of the alternative hypotheses already presented in the literature. Often this is the case due to identities, or similarities, in the step-wise mechanisms, in 


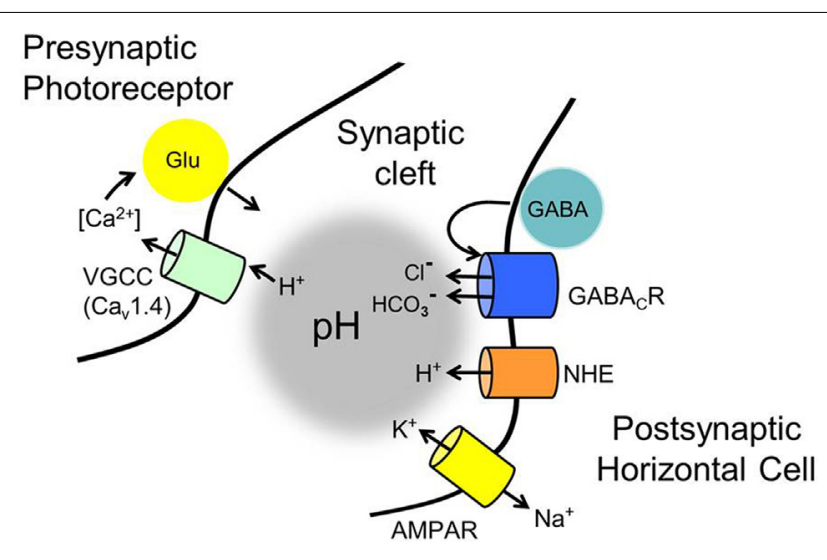

FIGURE 12 | Membrane mechanisms identified in the GABA-pH hybrid model of feedback that have roles in modulating the $\mathrm{pH}$ of the mammalian photoreceptor synaptic cleft. Standing as the foundation of the feedback mechanism are voltage-gated Cav1.4 channels in photoreceptors that ultimately regulate glutamate release. Notwithstanding ephaptic-coupled voltage changes of the cleft, never identified in mammalian retinas, regulation of the Cav channels by surface charge screening due to cleft $\mathrm{pH}$ changes has proven to be a powerful modulator of glutamate release. Contributors to cleft $\mathrm{pH}$ implicated in the current review include: (1) tonic autaptic release and reception of GABA by horizontal cells (only mammalian horizontal cells appear to release GABA via a vesicular mechanism, but an alternate mechanism, reversed GABA uptake, operates in many vertebrates). (2) While GABA release is controlled by horizontal cell Cav channels, evidence indicates that significant GABA levels are tonically present in the cleft, under light and dark-adapted conditions, and only change via membrane potential on longer time scales. (3) Tonic activation of $\rho$ subunit containing GABARs provides $\mathrm{HCO}_{3}^{-}$efflux, whose amplitude is regulated by the driving force determined by the horizontal cell membrane potential, which is influenced strongly by photoreceptor glutamate release onto horizontal cell AMPARs, and the equilibrium potential for $\mathrm{HCO}_{3}^{-}$. (4) $\mathrm{HCO}_{3}^{-}$efflux and depolarization-modulated proton extrusion via NHEs compete to change cleft $\mathrm{pH}$. These steps result in the regulation of cone glutamate release in a manner dependent on horizontal cell $V_{\mathrm{m}}$ and this underlies the surround inhibition and regulation of synaptic strength, the hallmarks of horizontal cell feedback to cones.

non-mammalian and mammalian retinas. For example, whereas vesicular GABA release and its autaptic reception by horizontal cells is a key event in the GABA-pH model reviewed here, in fish and non-mammalian vertebrate retinas, the vesicular release seems to be replaced by reversed GAT-mediated uptake (Marc et al., 1978; Schwartz, 2002), which mammalian horizontal cells lack (Blanks and Roffler-Tarlov, 1982; Pow et al., 1996). The $\mathrm{HCO}_{3}^{-}$permeability of the GABARs should be biophysically conserved in all GABARs, requiring no species-specific claim. The $\mathrm{pH}$-dependence of feedback is reported throughout studies in vertebrate retinas, and any change to the retinal environment that alters $\mathrm{pH}$ buffering or changes the $\mathrm{pH}$ is well-recognized as being capable of modulating the voltage-dependence of photoreceptor $\mathrm{Ca}_{\mathrm{V}}$ channel activation. Hepes (and other $\mathrm{pH}$ buffers) block feedback in all models, suggesting a broadly consistent mechanism, albeit mediated by different mechanisms ( $\mathrm{pH}$ buffering by $\mathrm{HCO}_{3}^{-}$in mammals vs. ATP hydrolysis in fish), but given a cytoplasm-acidifying alibi in the case of hemichannel ephaptic feedback (Vroman et al., 2014). The model reported in Grove et al. (2019) might not extend to all non-mammalian vertebrate species as some horizontal cell subtypes do not stain for GABA.

Feedback is considered to consist of several components (Warren et al., 2016b; Cenedese et al., 2017) that would function over different timescales. Analysis of the data of Grove et al. (2019) suggest three components, the slowest being the "tonic" presence of GABA in the OPL, which is expected to change on a scale of $10-100 \mathrm{~min}$ as the presence of GABA persists in the OPL. This component blends into the temporal range of and may be considered a part of, broader mechanisms of light and dark adaptation. A second, slow component is the depolarizationinduced metabolic acidification of the OPL, operating on a scale of 10-100 s; and the GABA-pH model has a third and very fast component that involves membrane potential driven $\mathrm{HCO}_{3}^{-}$flux in GABAR channels, presumably in the millisecond range. Most of the experiments reviewed from Grove et al. (2019) studied feedback actions that involve all three components, with only the first and slowest generally held constant given the mesopic lightadapted conditions.

The speed of feedback is a very important issue and it has been argued effectively that there are fast and slow components in zebrafish. In zebrafish, the fast component is accounted for by the virtually instantaneous hemichannelmediated ephaptic coupling, and the much slower component is caused by pannexin-mediated ATP release and resultant pH buffering action (Cenedese et al., 2017). In zebrafish, it has been suggested that GABA could also play a modulatory role in feedback, acting at the photoreceptor membrane, and switching feedback off during dark adaptation (Klaassen et al., 2011). Whereas the GABA-mediated modulation of feedback via cone GABARs is considered in zebrafish to be much slower than either of these (Klaassen et al., 2011), the GABA-pH model assigns GABA concentration as being essentially tonic, a condition that might be due to a low vesicular release rate (although still calcium-mediated) and the lack of uptake or degradation within the synaptic invagination (Grove et al., 2019). The existence of a constant $\mathrm{HCO}_{3}^{-}$semi-permeable membrane allows the $\mathrm{pH}$-influencing effect in the cleft to be the fast component of feedback in this model, albeit it is somewhat slower than the truly instantaneous ephaptic coupling. It may be under-appreciated that the GABA-pH hybrid model attributes the tonic presence of GABA in the outer retina, experimentally confirmed in many of the figures in this review, as a gate for the presence of feedback. Once given this tonic GABA presence, changes to cleft $\mathrm{pH}$ are temporally linked to the speed of membrane potential change, as changes in horizontal cell membrane potential immediately change the driving force on $\mathrm{HCO}_{3}^{-}$, followed by ion flux but not channel gating.

Some features of the different models are less amenable to interspecies conservation, a good example being the requirement for hemichannels in ephaptic feedback and their absence in mammalian retinas, suggesting that there is not hemichannel mediated feedback in mammalian retinas. This does not exclude AMPARs playing the traditional electric feedback role (Byzov and Shura-Bura, 1986). However, Warren et al. (2016b) carefully determined the instrument delay-corrected feedback timescales 
in salamander retina, finding the fastest time constant of feedback to be 9-13 and 116-216 ms for the slower component. A $\sim 10 \mathrm{~ms}$ time constant is much slower than what is expected for an instantaneous ephaptic voltage change, discounting the traditional electric feedback by AMPARs (Byzov and ShuraBura, 1986; Kamermans et al., 2001), but not a fast ion diffusion model.

\section{Dark-induced Acidification and Non-linear Proton Extrusion}

The origin of dark-induced acidification in the OPL (Figure 2) lies with: (1) the sustained, depolarized state of photoreceptors, OFF-bipolar cells and horizontal cells in the dark; (2) their metabolic requirements to maintain ionic gradients under these conditions; and (3) the reactions by which mitochondria generate ATP. The metabolic demand arises principally from pumping ions by $\mathrm{Na}^{+} / \mathrm{K}^{+}$-ATPases, which utilize 1 ATP for every $3 \mathrm{Na}^{+}$ pumped out in exchange for $2 \mathrm{~K}^{+}$brought into the cell (Stahl, 1986), and to a lesser degree to cytosolic $\mathrm{Ca}^{+}$extrusion by $\mathrm{Ca}^{2+}$-ATPases. The chemiosmotic theory holds that the synthesis of each ATP catalyzed by the $\mathrm{H}^{+}$-ATP synthase is coupled to the translocation of three to five protons depending on the type of synthase, from the internal mitochondrial compartment to the cytoplasm (Petersen et al., 2012) and, to maintain cytoplasmic $\mathrm{pH}$, protons are extruded to the extracellular space principally via NHEs, producing extracellular acidification. When NHEs were blocked with cariporide or amiloride, inhibitory feedback was lost and there was no further regulation by TPMPA (Figure 10), providing evidence that NHE extrusion of protons into the extracellular space contributes significantly to extracellular acidification at the synaptic cleft (Warren et al., 2016a; Grove et al., 2019). This finding that horizontal cell GABAR-mediated cleft acidification is dependent on NHE proton extrusion supports a role for depolarizationmediated production and extrusion of protons in horizontal cell feedback. Although electroneutral, activation of the $\mathrm{H}^{+}$extruder NHE is itself exponentially related to $\mathrm{pH}_{\mathrm{i}}$ (Aronson et al., 1982) and NHE increases outward proton flux steeply due to its sensitivity to intracellular calcium and $\mathrm{pH}_{\mathrm{i}}$ (Aronson et al., 1982; Madshus, 1988; Bertrand et al., 1994; Ma and Haddad, 1997; Koster et al., 2011). This causes perisynaptic NHE $\mathrm{H}^{+}$efflux to increase exponentially with horizontal cell depolarization.

It is likely that, in low low-light conditions, depolarized photoreceptors, OFF bipolar cells, and horizontal cells contribute to this tonic acidifying influence that inhibits photoreceptor $\mathrm{Ca}_{V}$ channels. Since the role of the horizontal cell is to modulate photoreceptor output, horizontal cells limit this acidification by also introducing a $\mathrm{pH}$ buffer to the cleft $\mathrm{pH}$ as a function of their membrane potential. Cleft $\mathrm{pH}$ can rapidly increase during horizontal cell hyperpolarization due to voltage-driven efflux of $\mathrm{HCO}_{3}^{-}$via tonically active GABARs.

\section{GABA Was Previously and Erroneously Rejected as the Feedback Transmitter}

Voltage clamp recordings of inward current induced by "pure" surround illumination upon the already standing spot response in mammals (Verweij et al., 2003) presents an outstanding example of the unintuitive nature of the actions underlying the GABA-pH hybrid model. In these experiments, a cone was stimulated with a small spot of light but was voltageclamped at $-40 \mathrm{mV}$, well within the activation range of cone $\mathrm{Ca}_{\mathrm{v}}$, allowing glutamate release. The horizontal cell synaptic tips responding to the glutamate would be depolarized in these experiments. According to the GABA-pH hybrid model, GABA should decrease $\mathrm{pH}_{\mathrm{O}}$ under these conditions. This is indeed what was found to occur; superfusion of GABA decreased feedback, while picrotoxin increased it. Surround-evoked inward currents persisted in picrotoxin and GABA, albeit with magnitudes that follow the shifted Cav activation curves shown here in cones voltage-clamped at $-40 \mathrm{mV}$, and treated with picrotoxin and muscimol. Verweij et al.'s (2003) results do rule out a role for GABA if interpreted in the context that the GABARs would be on cones, not horizontal cells. The direct action of GABARs at the cone would have led to a block of surround-induced inward current changes when they applied either picrotoxin or GABA. Instead, the result presented is consistent with the autaptic GABA-pH feedback mechanism. Such an action is not predicted by any other of the existing models proposed for feedback and appears to reflect the full extent of the actions of feedback from horizontal cells to voltage-clamped cones, underscoring the differences seen in non-mammalian vertebrates, where cones express GABARs (Wu, 1991; Endeman et al., 2012).

The inconsistent effects of picrotoxin on horizontal cell feedback have been an additional confound in some earlier feedback models testing GABA as a potential transmitter. Studies that failed to find an effect with picrotoxin may have suffered from a late-emerging oversight. Due to the addition of a methionine residue in some species' $\rho 2$ subunits, their GABARs may be less sensitive to picrotoxin block (Zhang et al., 1995; Greka et al., 1998). The observation of GABAergic effects at relatively high concentrations of picrotoxin compared against those using standard concentrations of the selective $\rho$-subunit-containing GABAR antagonist TPMPA $(50 \mu \mathrm{M})$, alongside mouse $\rho 2$ GABAR immunostaining (Grove et al., 2019), suggest that studies testing the effects of picrotoxin using low concentrations could be compromised.

\section{GABA and pH Linked Actions Throughout the Brain}

Changes in extracellular acidity in response to GABAergic activity have been described throughout the brain (Chesler, 2003; Farrant and Kaila, 2007; Ruusuvuori and Kaila, 2014). These are fundamentally similar to the GABA- and pH-mediated signaling in horizontal cell feedback but differ in detail. Most are mechanisms that share $\mathrm{pH}$ changing properties that affect synaptic acidification at GABA and glycinergic synapses elsewhere in the brain. In comparison, the GABA and $\mathrm{pH}$-mediated effects in the horizontal cell to photoreceptor feedback represent a new form of synaptic inhibition in a graded potential network, and related $\mathrm{pH}$-mediated modulations of synaptic interactions have been described in the CNS in action 
potential-dependent neurotransmission (Chesler, 2003; Farrant and Kaila, 2007; Ruusuvuori and Kaila, 2014).

In the olfactory bulb, signal processing requirements differ greatly from those in the eye. Synapses formed by olfactory receptors with periglomerular interneurons utilize GABAergic presynaptic feedback to modulate presynaptic Ca channels, albeit in a different manner than at photoreceptor synapses (McGann, 2013). This presynaptic inhibition has several roles, including the regulation of synaptic gain, and the generation of odorant filters that could sharpen olfactory discrimination. In the retina, inhibitory feedback to photoreceptors by horizontal cells functions to sharpen special contrast differences and to tune the response frequencies sensed by downstream retinal neurons, in a manner that sharpens temporal sensitivity.

The mechanisms reviewed here presented as changes to voltage-clamped $\mathrm{Ca}_{V}$ currents in cones and probed via the net effects of pharmacological manipulations, provide insight into steady-state levels of feedback. While all interventions that modulate the activation of the $\mathrm{Ca}_{V}$ current are not necessarily related to feedback from horizontal cells to photoreceptors, the dissection of steady-state conditions that effect feedback

\section{REFERENCES}

Achilles, K., Okabe, A., Ikeda, M., Shimizu-Okabe, C., Yamada, J., Fukuda, A., et al. (2007). Kinetic properties of $\mathrm{Cl}$ uptake mediated by $\mathrm{Na}^{+}$-dependent $\mathrm{K}^{+}-2 \mathrm{Cl}^{-}$ cotransport in immature rat neocortical neurons. J. Neurosci. 27, 8616-8627. doi: 10.1523/JNEUROSCI.5041-06.2007

Ames, A. III, Li, Y. Y., Heher, E. C., and Kimble, C. R. (1992). Energy metabolism of rabbit retina as related to function: high cost of $\mathrm{Na}^{+}$transport. J. Neurosci. 12, 840-853. doi: 10.1523/JNEUROSCI.12-03-00840.1992

Aronson, J. K., Moore, M. P., Redman, C. W., and Harper, C. (1982). Sodiumlithium countertransport in erythrocytes of pregnant women. N. Engl. J. Med. 307, 1645-1646. doi: 10.1056/NEJM198212233072615

Ashiya, M., Zhang, L., and Grabowski, P. J. (1995). Regulated splicing of gamma2 pre-messenger RNA in neuronal cells. Nucleic Acids Symp. Ser. 33, 215-216.

Ayoub, G. S., and Lam, D. M. (1984). The release of gamma-aminobutyric acid from horizontal cells of the goldfish (Carassius auratus) retina. J. Physiol. 355, 191-214. doi: 10.1113/jphysiol.1984.sp015414

Babai, N., and Thoreson, W. B. (2009). Horizontal cell feedback regulates calcium currents and intracellular calcium levels in rod photoreceptors of salamander and mouse retina. J. Physiol. 587, 2353-2364. doi: 10.1113/jphysiol.2009.169656

Barnes, S., and Bui, Q. (1991). Modulation of calcium-activated chloride current via $\mathrm{pH}$-induced changes of calcium channel properties in cone photoreceptors. J. Neurosci. 11, 4015-4023. doi: 10.1523/JNEUROSCI.11-12-04015.1991

Barnes, S., Merchant, V., and Mahmud, F. (1993). Modulation of transmission gain by protons at the photoreceptor output synapse. Proc. Natl. Acad. Sci. U S A 90, 10081-10085. doi: 10.1073/pnas.90.21.10081

Baylor, D. A., Fuortes, M. G., and O’Bryan, P. M. (1971). Receptive fields of cones in the retina of the turtle. J. Physiol. 214, 265-294. doi: 10.1113/jphysiol.1971. sp009432

Beaumont, M., and Maccaferri, G. (2011). Is connexin36 critical for GABAergic hypersynchronization in the hippocampus? J. Physiol. 589, 1663-1680. doi: 10.1113/jphysiol.2010.201491

Beckwith-Cohen, B., Holzhausen, L. C., Wang, T.-M., Rajappa, R., and Kramer, R. H. (2019). Localizing proton-mediated inhibitory feedback at the retinal horizontal cell-cone synapse with genetically-encoded $\mathrm{pH}$ probes. J. Neurosci. 39, 651-662. doi: 10.1523/JNEUROSCI.1541-18.2018

Bertrand, B., Wakabayashi, S., Ikeda, T., Pouyssegur, J., and Shigekawa, M. (1994). The $\mathrm{Na}^{+} / \mathrm{H}^{+}$exchanger isoform 1 (NHE1) is a novel member of the calmodulin-binding proteins. Identification and characterization of calmodulin-binding sites. J. Biol. Chem. 269, 13703-13709. clarify in a stepwise manner the pathway that accounts for feedback. To fully appreciate this synaptic mechanism, all of these aspects should be considered simultaneously. A greater understanding of this novel feedback mechanism will be achieved with further testing using non-steady-state light conditions.

\section{AUTHOR CONTRIBUTIONS}

All authors: data curation, investigation, visualization, writing-review and editing. All authors contributed to the article and approved the submitted version.

\section{FUNDING}

This work was supported by grants from the Plum Foundation (SB); Glaucoma Research Foundation (SB); UCLA Council on Research Faculty Grant (SB); National Eye Institute (NIH) EY04067, EY15573, and EY29869 (NB); VA Senior Career Scientist Award (NB), and an Unrestricted Grant from Research to Prevent Blindness, Incorporation (UCLA Department of Ophthalmology).

Blanks, J. C., and Roffler-Tarlov, S. (1982). Differential localization of radioactive gamma-aminobutyric acid and muscimol in isolated and in vivo mouse retina. Exp. Eye Res. 35, 573-584. doi: 10.1016/s0014-4835(82)80071-7

Bolton, T. B., and Vaughan-Jones, R. D. (1977). Continuous direct measurement of intracellular chloride and pH in frog skeletal muscle. J. Physiol. 270, 801-833. doi: 10.1113/jphysiol.1977.sp011983

Borgula, G. A., Karwoski, C. J., and Steinberg, R. H. (1989). Light-evoked changes in extracellular pH in frog retina. Vision Res. 29, 1069-1077. doi: 10.1016/00426989(89)90054-0

Bormann, J. (2000). The 'ABC' of GABA receptors. Trends Pharmacol. Sci. 21, 16-19. doi: 10.1016/s0165-6147(99)01413-3

Bormann, J., Hamill, O. P., and Sakmann, B. (1987). Mechanism of anion permeation through channels gated by glycine and gamma-aminobutyric acid in mouse cultured spinal neurones. J. Physiol. 385, 243-286. doi: 10.1113/jphysiol.1987.sp016493

Brandon, C., and Lam, D. M. (1983). The ultrastructure of rat rod synaptic terminals: effects of dark-adaptation. J. Comp. Neurol. 217, 167-175. doi: 10.1002/cne. 902170205

Bringmann, A., Grosche, A., Pannicke, T., and Reichenbach, A. (2013). GABA and glutamate uptake and metabolism in retinal glial (muller) cells. Front. Endocrinol. 4:48. doi: 10.3389/fendo.2013.00048

Burkhardt, D. A. (1993). Synaptic feedback, depolarization and color opponency in cone photoreceptors. Vis. Neurosci. 10, 981-989. doi: 10.1017/s0952523800010087

Byzov, A. L. (1977). Model for the feedback mechanism between horizontal cells and photoreceptors of vertebrate retinas. Neirofiziologiia 9, 86-94.

Byzov, A. L., and Shura-Bura, T. M. (1986). Electrical feedback mechanism in the processing of signals in the outer plexiform layer of the retina. Vision Res. 26, 33-44. doi: 10.1016/0042-6989(86)90069-6

Byzov, A. L., Trifonov, Y. A., Chailahian, L. M., and Golubtzov, K. W. (1977). Amplification of graded potentials in horizontal cells of the retina. Vision Res. 17, 265-273. doi: 10.1016/0042-6989(77)90090-6

Cadetti, L., and Thoreson, W. B. (2006). Feedback effects of horizontal cell membrane potential on cone calcium currents studied with simultaneous recordings. J. Neurophysiol. 95, 1992-1995. doi: 10.1152/jn. 01042.2005

Catsicas, S., Catsicas, M., Keyser, K. T., Karten, H. J., Wilson, M. C., and Milner, R. J. (1992). Differential expression of the presynaptic protein SNAP-25 in mammalian retina. J. Neurosci. Res. 33, 1-9. doi: 10.1002/jnr.4903 30102 
Cenedese, V., de Graaff, W., Csikos, T., Poovayya, M., Zoidl, G., and Kamermans, M. (2017). Pannexin 1 is critically involved in feedback from horizontal cells to cones. Front. Mol. Neurosci. 10:403. doi: 10.3389/fnmol.2017. 00403

Chaffiol, A., Ishii, M., Cao, Y., and Mangel, S. C. (2017). Dopamine regulation of $\mathrm{GABA}_{A}$ receptors contributes to light/dark modulation of the ON-cone bipolar cell receptive feld surround in the retina. Curr. Biol. 27, 2600.e4-2609.e4. doi: 10.1016/j.cub.2017.07.063

Chesler, M. (2003). Regulation and modulation of $\mathrm{pH}$ in the brain. Physiol. Rev. 83, 1183-1221. doi: 10.1152/physrev.00010.2003

Connors, B. W. (2012). Tales of a dirty drug: carbenoxolone, gap junctions and seizures. Epilepsy Curr. 12, 66-68. doi: 10.5698/1535-7511-12.2.66

Crook, J. D., Davenport, C. M., Peterson, B. B., Packer, O. S., Detwiler, P. B., and Dacey, D. M. (2009). Parallel ON and OFF cone bipolar inputs establish spatially coextensive receptive field structure of blue-yellow ganglion cells in primate retina. J. Neurosci. 29, 8372-8387. doi: 10.1523/JNEUROSCI.121809.2009

Cueva, J. G., Haverkamp, S., Reimer, R. J., Edwards, R., Wässle, H., and Brecha, N. C. (2002). Vesicular gamma-aminobutyric acid transporter expression in amacrine and horizontal cells. J. Comp. Neurol. 445, 227-237. doi: $10.1002 /$ cne. 10166

Dacey, D., Packer, O. S., Diller, L., Brainard, D., Peterson, B., and Lee, B. (2000). Center surround receptive field structure of cone bipolar cells in primate retina. Vision Res. 40, 1801-1811. doi: 10.1016/s0042-6989(00) 00039-0

Davenport, C. M., Detwiler, P. B., and Dacey, D. M. (2008). Effects of pH buffering on horizontal and ganglion cell light responses in primate retina: evidence for the proton hypothesis of surround formation. J. Neurosci. 28, 456-464. doi: 10.1523/JNEUROSCI.2735-07.2008

Deniz, S., Wersinger, E., Picaud, S., and Roux, M. J. (2019). Evidence for functional GABAA but not GABAC receptors in mouse cone photoreceptors. Vis. Neurosci. 36:E005. doi: 10.1017/S0952523819000038

Deniz, S., Wersinger, E., Schwab, Y., Mura, C., Erdelyi, F., Szabo, G., et al. (2011). Mammalian retinal horizontal cells are unconventional GABAergic neurons. J. Neurochem. 116, 350-362. doi: 10.1111/j.1471-4159.2010.07114.x

DeVries, S. H. (2001). Exocytosed protons feedback to suppress the $\mathrm{Ca}^{2+}$ current in mammalian cone photoreceptors. Neuron 32, 1107-1117. doi: 10.1016/s0896-6273(01)00535-9

Djamgoz, M. B., and Laming, P. J. (1987). Intracellular potassium activities of horizontal cells and extracellular potassium activity in isolated retinae of a cyprinid fish. Vision Res. 27, 711-721. doi: 10.1016/0042-6989(87)90068-x

Dmitriev, A. V., and Mangel, S. C. (2004). Retinal pH reflects retinal energy metabolism in the day and night. J. Neurophysiol. 91, 2404-2412. doi: $10.1152 /$ jn. 00881.2003

Dmitriev, A. V., Henderson, D., and Linsenmeier, R. A. (2016). Light-induced pH changes in the intact retinae of normal and early diabetic rats. Exp. Eye Res. 145, 148-157. doi: 10.1016/j.exer.2015.11.015

Dong, C. J., Picaud, S. A., and Werblin, F. S. (1994). GABA transporters and GABAC-like receptors on catfish cone- but not rod-driven horizontal cells. J. Neurosci. 14, 2648-2658. doi: 10.1523/JNEUROSCI.14-05-02648. 1994

Dowling, J. E., and Boycott, B. B. (1966). Organization of the primate retina: electron microscopy. Proc. R. Soc. Lond. B Biol. Sci. 166, 80-111. doi: $10.1098 / \mathrm{rspb} .1966 .0086$

Duebel, J., Haverkamp, S., Schleich, W., Feng, G., Augustine, G. J., Kuner, T., et al. (2006). Two-photon imaging reveals somatodendritic chloride gradient in retinal ON-type bipolar cells expressing the biosensor clomeleon. Neuron 49, 81-94. doi: 10.1016/j.neuron.2005.10.035

Endeman, D., Fahrenfort, I., Sjoerdsma, T., Steijaert, M., Ten Eikelder, H., and Kamermans, M. (2012). Chloride currents in cones modify feedback from horizontal cells to cones in goldfish retina. J. Physiol. 590, 5581-5595. doi: 10.1113/jphysiol.2012.240325

Enz, R., Brandstätter, J. H., Wässle, H., and Bormann, J. (1996). Immunocytochemical localization of the GABAc receptor rho subunits in the mammalian retina. J. Neurosci. 16, 4479-4490. doi: 10.1523/JNEUROSCI. 16-14-04479.1996

Fahrenfort, I., Klooster, J., Sjoerdsma, T., and Kamermans, M. (2005). The involvement of glutamate-gated channels in negative feedback from horizontal cells to cones. Prog. Brain Res. 147, 219-229. doi: 10.1016/S00796123(04)47017-4

Fahrenfort, I., Steijaert, M., Sjoerdsma, T., Vickers, E., Ripps, H., van Asselt, J., et al. (2009). Hemichannel-mediated and pH-based feedback from horizontal cells to cones in the vertebrate retina. PLoS One 4:e6090. doi: 10.1371/journal. pone.0006090

Farrant, M., and Kaila, K. (2007). The cellular, molecular and ionic basis of GABA(A) receptor signalling. Prog. Brain Res. 160, 59-87. doi: 10.1016/S00796123(06)60005-8

Fatima-Shad, K., and Barry, P. H. (1993). Anion permeation in GABA- and glycine-gated channels of mammalian cultured hippocampal neurons. Proc. Biol. Sci. 253, 69-75. doi: 10.1098/rspb.1993.0083

Feigenspan, A., and Weiler, R. (2004). Electrophysiological properties of mouse horizontal cell GABAA receptors. J. Neurophysiol. 92, 2789-2801. doi: 10.1152/jn.00284.2004

Gilbertson, T. A., Borges, S., and Wilson, M. (1991). The effects of glycine and GABA on isolated horizontal cells from the salamander retina. J. Neurophysiol. 66, 2002-2013. doi: 10.1152/jn.1991.66.6.2002

Grabs, D., Bergmann, M., Urban, M., Post, A., and Gratzl, M. (1996). Rab3 proteins and SNAP-25, essential components of the exocytosis machinery in conventional synapses, are absent from ribbon synapses of the mouse retina. Eur. J. Neurosci. 8, 162-168. doi: 10.1111/j.1460-9568.1996.tb01177.x

Greenlee, M. H., Roosevelt, C. B., and Sakaguchi, D. S. (2001). Differential localization of SNARE complex proteins SNAP-25, syntaxin and VAMP during development of the mammalian retina. J. Comp. Neurol. 430, 306-320. doi: 10.1002/1096-9861(20010212)430:3<306::aid-cne1032>3.0.co;2-b

Greferath, U., Müller, F., Wässle, H., Shivers, B., and Seeburg, P. (1993). Localization of GABAA receptors in the rat retina. Vis. Neurosci. 10, 551-561. doi: 10.1017/s0952523800004764

Greka, A., Koolen, J. A., Lipton, S. A., and Zhang, D. (1998). Cloning and characterization of mouse GABA(C) receptor subunits. Neuroreport 9, 229-232. doi: 10.1097/00001756-199801260-00010

Grigorenko, E. V., and Yeh, H. H. (1994). Expression profiling of GABAA receptor beta-subunits in the rat retina. Vis. Neurosci. 11, 379-387. doi: $10.1017 / \mathrm{s} 0952523800001723$

Grove, J. C. R., Hirano, A. A., de Los Santos, J., McHugh, C. F., Purohit, S., Field, G. D., et al. (2019). Novel hybrid action of GABA mediates inhibitory feedback in the mammalian retina. PLoS Biol. 17:e3000200. doi: 10.1371/journal.pbio.3000200

Grünert, U., and Wässle, H. (1990). GABA-like immunoreactivity in the macaque monkey retina: a light and electron microscopic study. J. Comp. Neurol. 297, 509-524. doi: 10.1002/cne.902970405

Guo, C., Hirano, A. A., Stella, S. L. Jr., Bitzer, M., and Brecha, N. C. (2010). Guinea pig horizontal cells express GABA, the GABA-synthesizing enzyme GAD 65 and the GABA vesicular transporter. J. Comp. Neurol. 518, 1647-1669. doi: $10.1002 / \mathrm{cne} .22294$

Guo, C., Stella, S. L. Jr., Hirano, A. A., and Brecha, N. C. (2009). Plasmalemmal and vesicular gamma-aminobutyric acid transporter expression in the developing mouse retina. J. Comp. Neurol. 512, 6-26. doi: 10.1002/cne. 21846

Haverkamp, S., and Wässle, H. (2000). Immunocytochemical analysis of the mouse retina. J. Comp. Neurol. 424, 1-23. doi: 10.1002/10969861(20000814)424:1<1::AID-CNE1>3.0.CO;2-V

Haverkamp, S., Grünert, U., and Wässle, H. (2000). The cone pedicle, a complex synapse in the retina. Neuron 27, 85-95. doi: 10.1016/s0896-6273(00) 00011-8

Hille, B. (1968). Charges and potentials at the nerve surface. Divalent ions and $\mathrm{pH}$. J. Gen. Physiol. 51, 221-236. doi: 10.1085/jgp.51.2.221

Hirano, A. A., Brandstätter, J. H., and Brecha, N. C. (2005). Cellular distribution and subcellular localization of molecular components of vesicular transmitter release in horizontal cells of rabbit retina. J. Comp. Neurol. 488, 70-81. doi: 10.1002/cne.20577

Hirano, A. A., Brandstätter, J. H., Morgans, C. W., and Brecha, N. C. (2011). SNAP25 expression in mammalian retinal horizontal cells. J. Comp. Neurol. 519, 972-988. doi: 10.1002/cne.22562

Hirano, A. A., Brandstätter, J. H., Vila, A., and Brecha, N. C. (2007). Robust syntaxin-4 immunoreactivity in mammalian horizontal cell processes. Vis. Neurosci. 24, 489-502. doi: 10.1017/S0952523807070198 
Hirano, A. A., Liu, X., Boulter, J., Grove, J., Perez de Sevilla Müller, L., Barnes, S., et al. (2016). Targeted deletion of vesicular GABA transporter from retinal horizontal cells eliminates feedback modulation of photoreceptor calcium channels. eNeuro 3:ENEURO.0148-15.2016. doi: 10.1523/ENEURO.014815.2016

Hirasawa, H., and Kaneko, A. (2003). pH changes in the invaginating synaptic cleft mediate feedback from horizontal cells to cone photoreceptors by modulating $\mathrm{Ca}^{2+}$ channels. J. Gen. Physiol. 122, 657-671. doi: 10.1085/jgp.200308863

Hoon, M., Sinha, R., Okawa, H., Suzuki, S. C., Hirano, A. A., Brecha, N., et al. (2015). Neurotransmission plays contrasting roles in the maturation of inhibitory synapses on axons and dendrites of retinal bipolar cells. Proc. Natl. Acad. Sci. U S A 112, 12840-12845. doi: 10.1073/pnas.1510483112

Hubner, C. A., and Holthoff, K. (2013). Anion transport and GABA signaling. Front. Cell. Neurosci. 7:177. doi: 10.3389/fncel.2013.00177

Jackman, S. L., Babai, N., Chambers, J. J., Thoreson, W. B., and Kramer, R. H. (2011). A positive feedback synapse from retinal horizontal cells to cone photoreceptors. PLoS Biol. 9:e1001057. doi: 10.1371/journal.pbio.1001057

Janssen-Bienhold, U., Schultz, K., Gellhaus, A., Schmidt, P., Ammermüller, J., and Weiler, R. (2001a). Identification and localization of connexin26 within the photoreceptor-horizontal cell synaptic complex. Vis. Neurosci. 18, 169-178. doi: $10.1017 /$ s0952523801182015

Janssen-Bienhold, U., Schultz, K., Hoppenstedt, W., and Weiler, R. (2001b). Molecular diversity of gap junctions between horizontal cells. Prog. Brain Res. 131, 93-107. doi: 10.1016/s0079-6123(01)31010-5

Johnson, J., Chen, T. K., Rickman, D. W., Evans, C., and Brecha, N. C. (1996). Multiple gamma-aminobutyric acid plasma membrane transporters (GAT-1, GAT-2, GAT-3) in the rat retina. J. Comp. Neurol. 375, 212-224. doi: 10.1002/(SICI)1096-9861(19961111)375:2<212::AID-CNE3>3.0.CO;2-5

Johnston, G. A. (2014). Muscimol as an ionotropic GABA receptor agonist. Neurochem. Res. 39, 1942-1947. doi: 10.1007/s11064-014-1245-y

Kaila, K., and Voipio, J. (1987). Postsynaptic fall in intracellular pH induced by GABA-activated bicarbonate conductance. Nature 330, 163-165. doi: $10.1038 / 330163 \mathrm{a} 0$

Kamermans, M., and Werblin, F. (1992). GABA-mediated positive autofeedback loop controls horizontal cell kinetics in tiger salamander retina. J. Neurosci. 12, 2451-2463. doi: 10.1523/JNEUROSCI.12-07-02451.1992

Kamermans, M., Fahrenfort, I., Schultz, K., Janssen-Bienhold, U., Sjoerdsma, T., and Weiler, R. (2001). Hemichannel-mediated inhibition in the outer retina. Science 292, 1178-1180. doi: 10.1126/science.1060101

Kemmler, R., Schultz, K., Dedek, K., Euler, T., and Schubert, T. (2014). Differential regulation of cone calcium signals by different horizontal cell feedback mechanisms in the mouse retina. J. Neurosci. 34, 11826-11843. doi: 10.1523/JNEUROSCI.0272-14.2014

Klaassen, L. J., Sun, Z., Steijaert, M. N., Bolte, P., Fahrenfort, I., Sjoerdsma, T., et al. (2011). Synaptic transmission from horizontal cells to cones is impaired by loss of connexin hemichannels. PLoS Biol. 9:e1001107. doi: 10.1371/journal.pbio. 1001107

Koster, S., Pavkov-Keller, T., Kuhlbrandt, W., and Yildiz, O. (2011). Structure of human $\mathrm{Na}^{+} / \mathrm{H}^{+}$exchanger NHE1 regulatory region in complex with calmodulin and $\mathrm{Ca}^{2+}$. J. Biol. Chem. 286, 40954-40961. doi: 10.1074/jbc.M111. 286906

Kramer, R. H., and Davenport, C. M. (2015). Lateral inhibition in the vertebrate retina: the case of the missing neurotransmitter. PLoS Biol. 13:e1002322. doi: 10.1371/journal.pbio.1002322

Kranz, K., Dorgau, B., Pottek, M., Herrling, R., Schultz, K., Bolte, P., et al. (2013). Expression of pannexin1 in the outer plexiform layer of the mouse retina and physiological impact of its knockout. J. Comp. Neurol. 521, 1119-1135. doi: 10.1002/cne.23223

Krizaj, D., and Copenhagen, D. R. (2002). Calcium regulation in photoreceptors. Front. Biosci. 7, d2023-d2044. doi: 10.2741/krizaj

Kurtenbach, S., Kurtenbach, S., and Zoidl, G. (2014). Emerging functions of pannexin 1 in the eye. Front. Cell. Neurosci. 8:263. doi: 10.3389/fncel.2014. 00263

Lam, D. M., Lasater, E. M., and Naka, K. I. (1978). Gamma-aminobutyric acid: a neurotransmitter candidate for cone horizontal cells of the catfish retina. Proc. Natl. Acad. Sci. U S A 75, 6310-6313. doi: 10.1073/pnas.75.12.6310

Lee, H., and Brecha, N. C. (2010). Immunocytochemical evidence for SNARE protein-dependent transmitter release from guinea pig horizontal cells. Eur. J. Neurosci. 31, 1388-1401. doi: 10.1111/j.1460-9568.2010. 07181. $\mathrm{x}$

Linberg, K. A., and Fisher, S. K. (1988). Ultrastructural evidence that horizontal cell axon terminals are presynaptic in the human retina. J. Comp. Neurol. 268, 281-297. doi: 10.1002/cne.902680211

Liu, X., Grove, J. C., Hirano, A. A., Brecha, N. C., and Barnes, S. (2016). Dopamine D1 receptor modulation of calcium channel currents in horizontal cells of mouse retina. J. Neurophysiol. 116, 686-697. doi: 10.1152/jn.00990.2015

Liu, X., Hirano, A. A., Sun, X., Brecha, N. C., and Barnes, S. (2013). Calcium channels in rat horizontal cells regulate feedback inhibition of photoreceptors through an unconventional GABA- and $\mathrm{pH}$-sensitive mechanism. J. Physiol. 591, 3309-3324. doi: 10.1113/jphysiol.2012.248179

Löhrke, S., and Hofmann, H. D. (1994). Voltage-gated currents of rabbit Aand B-type horizontal cells in retinal monolayer cultures. Vis. Neurosci. 11, 369-378. doi: 10.1017/s0952523800001711

Löscher, W., Puskarjov, M., and Kaila, K. (2013). Cation-chloride cotransporters NKCC1 and KCC2 as potential targets for novel antiepileptic and antiepileptogenic treatments. Neuropharmacology 69, 62-74. doi: 10.1016/j. neuropharm.2012.05.045

Ma, E., and Haddad, G. G. (1997). Expression and localization of $\mathrm{Na}^{+} / \mathrm{H}+$ exchangers in rat central nervous system. Neuroscience 79, 591-603. doi: 10.1016/s0306-4522(96)00674-4

Madshus, I. H. (1988). Regulation of intracellular pH in eukaryotic cells. Biochem. J. 250, 1-8. doi: 10.1042/bj2500001

Mangel, S. C. (1991). Analysis of the horizontal cell contribution to the receptive field surround of ganglion cells in the rabbit retina. J. Physiol. 442, 211-234. doi: 10.1113/jphysiol.1991.sp018790

Marc, R. E., Stell, W. K., Bok, D., and Lam, D. M. (1978). GABA-ergic pathways in the goldfish retina. J. Comp. Neurol. 182, 221-244. doi: 10.1002/cne.901820204

McGann, J. P. (2013). Presynaptic inhibition of olfactory sensory neurons: new mechanisms and potential functions. Chem. Senses 38, 459-474. doi: 10.1093/chemse/bjt018

Miller, R. F., and Dacheux, R. F. (1983). Intracellular chloride in retinal neurons: measurement and meaning. Vision Res. 23, 399-411. doi: 10.1016/00426989(83)90087-1

Montgelard, C., Forty, E., Arnal, V., and Matthee, C. A. (2008). Suprafamilial relationships among Rodentia and the phylogenetic effect of removing fast-evolving nucleotides in mitochondrial, exon and intron fragments. BMC Evol. Biol. 8:321. doi: 10.1186/1471-2148-8-321

Morgans, C. W. (2001). Localization of the alpha(1F) calcium channel subunit in the rat retina. Invest. Ophthalmol. Vis. Sci. 42, 2414-2418.

Morita, H., Fujiki, N., Hagiike, M., Yamaguchi, O., and Lee, K. (1999). Functional evidence for involvement of bumetanide-sensitive $\mathrm{Na}^{+} \mathrm{K}+2 \mathrm{CI}$ - cotransport in the hepatoportal $\mathrm{Na}^{+}$receptor of the sprague-dawley rat. Neurosci. Lett. 264, 65-68. doi: 10.1016/s0304-3940(99)00157-3

Nachman-Clewner, M., St Jules, R., and Townes-Anderson, E. (1999). L-type calcium channels in the photoreceptor ribbon synapse: localization and role in plasticity. J. Comp. Neurol. 415, 1-16.

Neumaier, F., Dibue-Adjei, M., Hescheler, J., and Schneider, T. (2015). Voltagegated calcium channels: determinants of channel function and modulation by inorganic cations. Prog. Neurobiol. 129, 1-36. doi: 10.1016/j.pneurobio.2014. 12.003

Niven, J. E., and Laughlin, S. B. (2008). Energy limitation as a selective pressure on the evolution of sensory systems. J. Exp. Biol. 211, 1792-1804. doi: 10.1242/jeb. 017574

Oakley, B. II, and Wen, R. (1989). Extracellular $\mathrm{pH}$ in the isolated retina of the toad in darkness and during illumination. J. Physiol. 419, 353-378. doi: 10.1113/jphysiol.1989.sp017876

Okawa, H., Sampath, A. P., Laughlin, S. B., and Fain, G. L. (2008). ATP consumption by mammalian rod photoreceptors in darkness and in light. Curr. Biol. 18, 1917-1921. doi: 10.1016/j.cub.2008.10.029

Pattnaik, B., Jellali, A., Sahel, J., Dreyfus, H., and Picaud, S. (2000). GABAC receptors are localized with microtubule-associated protein $1 \mathrm{~B}$ in mammalian cone photoreceptors. J. Neurosci. 20, 6789-6796. doi: 10.1523/JNEUROSCI.2018-06789.2000

Peters, A., Webster, H. D., and Palay, S. L. (1991). The Fine Structure of The Nervous System: Neurons and Their Supporting Cells. New York, NY: Oxford University Press. 
Petersen, J., Forster, K., Turina, P., and Graber, P. (2012). Comparison of the $\mathrm{H}+/$ ATP ratios of the $\mathrm{H}+$-ATP synthases from yeast and from chloroplast. Proc. Natl. Acad. Sci. U S A 109, 11150-11155. doi: 10.1073/pnas.1202799109

Picaud, S., Pattnaik, B., Hicks, D., Forster, V., Fontaine, V., Sahel, J., et al. (1998). GABAA and GABAC receptors in adult porcine cones: evidence from a photoreceptor-glia co-culture model. J. Physiol. 513, 33-42. doi: 10.1111/j. 1469-7793.1998.033by.x

Pottek, M., Hoppenstedt, W., Janssen-Bienhold, U., Schultz, K., Perlman, I., and Weiler, R. (2003). Contribution of connexin26 to electrical feedback inhibition in the turtle retina. J. Comp. Neurol. 466, 468-477. doi: 10.1002/cne. 10897

Pow, D. V., Baldridge, W., and Crook, D. K. (1996). Activity-dependent transport of GABA analogues into specific cell types demonstrated at high resolution using a novel immunocytochemical strategy. Neuroscience 73, 1129-1143. doi: 10.1016/0306-4522(96)00097-8

Rekling, J. C., Shao, X. M., and Feldman, J. L. (2000). Electrical coupling and excitatory synaptic transmission between rhythmogenic respiratory neurons in the preBotzinger complex. J. Neurosci. 20:RC113. doi: 10.1523/JNEUROSCI. 20-23-j0003.2000

Rivera, L., Blanco, R., and de la Villa, P. (2001). Calcium-permeable glutamate receptors in horizontal cells of the mammalian retina. Vis. Neurosci. 18, 995-1002. doi: 10.1017/S0952523801186165

Roos, A., and Boron, W. F. (1981). Intracellular pH. Physiol. Rev. 61, 296-434. doi: 10.1152/physrev.1981.61.2.296

Rouach, N., Segal, M., Koulakoff, A., Giaume, C., and Avignone, E. (2003). Carbenoxolone blockade of neuronal network activity in culture is not mediated by an action on gap junctions. J. Physiol. 553, 729-745. doi: 10.1113/jphysiol.2003.053439

Russell, J. M. (2000). Sodium-potassium-chloride cotransport. Physiol. Rev. 80, 211-276. doi: 10.1152/physrev.2000.80.1.211

Ruusuvuori, E., and Kaila, K. (2014). Carbonic anhydrases and brain pH in the control of neuronal excitability. Subcell. Biochem. 75, 271-290. doi: 10.1007/978-94-007-7359-2_14

Satoh, H., Kaneda, M., and Kaneko, A. (2001). Intracellular chloride concentration is higher in rod bipolar cells than in cone bipolar cells of the mouse retina. Neurosci. Lett. 310, 161-164. doi: 10.1016/s0304-3940(01)02120-6

Schnitzer, J., and Rusoff, A. C. (1984). Horizontal cells of the mouse retina contain glutamic acid decarboxylase-like immunoreactivity during early developmental stages. J. Neurosci. 4, 2948-2955. doi: 10.1523/JNEUROSCI.04-12-02948.1984

Schubert, T., Huckfeldt, R. M., Parker, E., Campbell, J. E., and Wong, R. O. (2010). Assembly of the outer retina in the absence of GABA synthesis in horizontal cells. Neural. Dev. 5:15. doi: 10.1186/1749-8104-5-15

Schubert, T., Weiler, R., and Feigenspan, A. (2006). Intracellular calcium is regulated by different pathways in horizontal cells of the mouse retina. J. Neurophysiol. 96, 1278-1292. doi: 10.1152/jn.00191.2006

Schwartz, E. A. (1982). Calcium-independent release of GABA from isolated horizontal cells of the toad retina. J. Physiol. 323, 211-227. doi: 10.1113/jphysiol.1982.sp014069

Schwartz, E. A. (1987). Depolarization without calcium can release gamma-aminobutyric acid from a retinal neuron. Science 238, 350-355. doi: $10.1126 /$ science. 2443977

Schwartz, E. A. (2002). Transport-mediated synapses in the retina. Physiol. Rev. 82, 875-891. doi: 10.1152/physrev.00010.2002

Skrzypek, J., and Werblin, F. (1983). Lateral interactions in absence of feedback to cones. J. Neurophysiol. 49, 1007-1016. doi: 10.1152/jn.1983.49.4.1007

Soto, E., Ortega-Ramirez, A., and Vega, R. (2018). Protons as messengers of intercellular communication in the nervous system. Front. Cell. Neurosci. 12:342. doi: 10.3389/fncel.2018.00342

Stahl, W. L. (1986). The Na,K-ATPase of nervous tissue. Neurochem. Int. 8, 449-476. doi: 10.1016/0197-0186(86)90179-8

Sun, X., Hirano, A. A., Brecha, N. C., and Barnes, S. (2017). Calciumactivated BKCa channels govern dynamic membrane depolarizations of horizontal cells in rodent retina. J. Physiol. 595, 4449-4465. doi: 10.1113/JP2 74132

Szikra, T., Trenholm, S., Drinnenberg, A., Juttner, J., Raics, Z., Farrow, K., et al. (2014). Rods in daylight act as relay cells for cone-driven horizontal cell-mediated surround inhibition. Nat. Neurosci. 17, 1728-1735. doi: $10.1038 / \mathrm{nn} .3852$
Tachibana, M., and Kaneko, A. (1986). Properties and functions of GABA-induced responses in turtle photoreceptors. Neurosci. Res. Suppl. 4, S85-S97. doi: 10.1016/0168-0102(86)90074-X

Takahashi, K., Miyoshi, S., Kaneko, A., and Copenhagen, D. R. (1995). Actions of nipecotic acid and SKF89976A on GABA transporter in cone-driven horizontal cells dissociated from the catfish retina. Jpn. J. Physiol. 45, 457-473. doi: 10.2170/jjphysiol.45.457

Takamori, S., Riedel, D., and Jahn, R. (2000). Immunoisolation of GABA-specific synaptic vesicles defines a functionally distinct subset of synaptic vesicles. J. Neurosci. 20, 4904-4911. doi: 10.1523/JNEUROSCI.20-1304904.2000

Tatsukawa, T., Hirasawa, H., Kaneko, A., and Kaneda, M. (2005). GABA-mediated component in the feedback response of turtle retinal cones. Vis. Neurosci. 22, 317-324. doi: 10.1017/S0952523805223076

Taylor, W. R., and Morgans, C. (1998). Localization and properties of voltagegated calcium channels in cone photoreceptors of tupaia belangeri. Vis. Neurosci. 15, 541-552. doi: 10.1017/s0952523898153142

Thoreson, W. B., and Mangel, S. C. (2012). Lateral interactions in the outer retina. Prog. Retin. Eye Res. 31, 407-441. doi: 10.1016/j.preteyeres.2012. 04.003

Thoreson, W. B., Babai, N., and Bartoletti, T. M. (2008). Feedback from horizontal cells to rod photoreceptors in vertebrate retina. J. Neurosci. 28, 5691-5695. doi: 10.1523/JNEUROSCI.0403-08.2008

Tovar, K. R., Maher, B. J., and Westbrook, G. L. (2009). Direct actions of carbenoxolone on synaptic transmission and neuronal membrane properties. J. Neurophysiol. 102, 974-978. doi: 10.1152/jn.00060.2009

Twig, G., Levy, H., and Perlman, I. (2003). Color opponency in horizontal cells of the vertebrate retina. Prog. Retin. Eye Res. 22, 31-68. doi: 10.1016/s13509462(02)00045-9

Ueda, Y., Kaneko, A., and Kaneda, M. (1992). Voltage-dependent ionic currents in solitary horizontal cells isolated from cat retina. J. Neurophysiol. 68, 1143-1150. doi: 10.1152/jn.1992.68.4.1143

Vardi, N., Kaufman, D. L., and Sterling, P. (1994). Horizontal cells in cat and monkey retina express different isoforms of glutamic acid decarboxylase. Vis. Neurosci. 11, 135-142. doi: 10.1017/s09525238000 11172

Vardi, N., Masarachia, P., and Sterling, P. (1992). Immunoreactivity to GABAA receptor in the outer plexiform layer of the cat retina. J. Comp. Neurol. 320, 394-397. doi: 10.1002/cne.903200310

Vardi, N., Morigiwa, K., Wang, T. L., Shi, Y. J., and Sterling, P. (1998). Neurochemistry of the mammalian cone "synaptic complex". Vision Res. 38, 1359-1369. doi: 10.1016/s0042-6989(98)00007-8

Vardi, N., Zhang, L. L., Payne, J. A., and Sterling, P. (2000). Evidence that different cation chloride cotransporters in retinal neurons allow opposite responses to GABA. J. Neurosci. 20, 7657-7663. doi: 10.1523/JNEUROSCI.20-20-07 657.2000

Varela, C., Blanco, R., and De la Villa, P. (2005). Depolarizing effect of GABA in rod bipolar cells of the mouse retina. Vision Res. 45, 2659-2667. doi: 10.1016/j. visres.2005.03.020

Verweij, J., Hornstein, E. P., and Schnapf, J. L. (2003). Surround antagonism in macaque cone photoreceptors. J. Neurosci. 23, 10249-10257. doi: 10.1523/JNEUROSCI.23-32-10249.2003

Verweij, J., Kamermans, M., and Spekreijse, H. (1996). Horizontal cells feed back to cones by shifting the cone calcium-current activation range. Vision Res. 36, 3943-3953. doi: 10.1016/s0042-6989(96)00142-3

Verweij, J., Kamermans, M., Negishi, K., and Spekreijse, H. (1998). GABA sensitivity of spectrally classified horizontal cells in goldfish retina. Vis Neurosci. 15, 77-86. doi: 10.1017/s0952523898151039

Vessey, J. P., Lalonde, M. R., Mizan, H. A., Welch, N. C., Kelly, M. E., and Barnes, S. (2004). Carbenoxolone inhibition of voltage-gated Ca channels and synaptic transmission in the retina. J. Neurophysiol. 92, 1252-1256. doi: 10.1152/jn. 00148.2004

Vessey, J. P., Stratis, A. K., Daniels, B. A., Da Silva, N., Jonz, M. G., Lalonde, M. R., et al. (2005). Proton-mediated feedback inhibition of presynaptic calcium channels at the cone photoreceptor synapse. J. Neurosci. 25, 4108-4117. doi: 10.1523/JNEUROSCI.5253-04.2005

Vroman, R., Klaassen, L. J., Howlett, M. H., Cenedese, V., Klooster, J., Sjoerdsma, T., et al. (2014). Extracellular ATP hydrolysis inhibits synaptic 
transmission by increasing ph buffering in the synaptic cleft. PLoS Biol. 12:e1001864. doi: 10.1371/journal.pbio.1001864

Vu, T. Q., Payne, J. A., and Copenhagen, D. R. (2000). Localization and developmental expression patterns of the neuronal K-Cl cotransporter (KCC2) in the rat retina. J. Neurosci. 20, 1414-1423. doi: 10.1523/JNEUROSCI.20-0401414.2000

Vuong, H. E., Kornmann, H. L., Stella, J. S. L., and Brecha, N. (2011). Gabaergic synaptic vesicles in guinea pig horizontal cells participate in $\mathrm{Ca}^{2+}$ dependent recycling. Invest. Ophthalmol. Vis. Sci. 52:4110.

Wang, T. M., Holzhausen, L. C., and Kramer, R. H. (2014). Imaging an optogenetic $\mathrm{pH}$ sensor reveals that protons mediate lateral inhibition in the retina. Nat. Neurosci. 17, 262-268. doi: 10.1038/nn.3627

Warren, T. J., Van Hook, M. J., Supuran, C. T., and Thoreson, W. B. (2016a). Sources of protons and a role for bicarbonate in inhibitory feedback from horizontal cells to cones in Ambystoma tigrinum retina. J. Physiol. 594, 6661-6677. doi: 10.1113/JP272533

Warren, T. J., Van Hook, M. J., Tranchina, D., and Thoreson, W. B. (2016b). Kinetics of inhibitory feedback from horizontal cells to photoreceptors: implications for an ephaptic mechanism. J. Neurosci. 36, 10075-10088. doi: 10.1523/JNEUROSCI.1090-16.2016

Wässle, H., and Chun, M. H. (1989). GABA-like immunoreactivity in the cat retina: light microscopy. J. Comp. Neurol. 279, 43-54. doi: 10.1002/cne. 902790105

Wässle, H., Koulen, P., Brandstätter, J. H., Fletcher, E. L., and Becker, C. M. (1998). Glycine and GABA receptors in the mammalian retina. Vision Res. 38, 1411-1430. doi: 10.1016/s0042-6989(97)00300-3

Wong-Riley, M. T. T. (2010). Energy metabolism of the visual system. Eye Brain 2, 99-116. doi: 10.2147/EB.S9078

Wu, S. M. (1991). Input-output relations of the feedback synapse between horizontal cells and cones in the tiger salamander retina. J. Neurophysiol. 65, 1197-1206. doi: 10.1152/jn.1991.65.5.1197

Wu, S. M. (1994). Synaptic transmission in the outer retina. Annu. Rev. Physiol. 56, 141-168. doi: 10.1146/annurev.ph.56.030194.001041
Wu, S. M. (2010). Synaptic organization of the vertebrate retina: general principles and species-specific variations: the friedenwald lecture. Invest. Ophthalmol. Vis. Sci. 51, 1263-1274. doi: 10.1167/iovs.09-4396

Wu, S. M., and Dowling, J. E. (1980). Effects of GABA and glycine on the distal cells of the cyprinid retina. Brain Res. 199, 401-414. doi: 10.1016/00068993(80)90697-6

Yamamoto, F., Borgula, G. A., and Steinberg, R. H. (1992). Effects of light and darkness on $\mathrm{pH}$ outside rod photoreceptors in the cat retina. Exp. Eye Res. 54, 685-697. doi: 10.1016/0014-4835(92)90023-1

Yang, X. L., Gao, F., and Wu, S. M. (1999). Modulation of horizontal cell function by $\mathrm{GABA}(\mathrm{A})$ and $\operatorname{GABA}(\mathrm{C})$ receptors in dark- and light-adapted tiger salamander retina. Vis. Neurosci. 16, 967-979. doi: 10.1017/s0952523899165167

Yazulla, S., and Kleinschmidt, J. (1983). Carrier-mediated release of GABA from retinal horizontal cells. Brain Res. 263, 63-75. doi: 10.1016/00068993(83)91201-5

Zhang, D., Pan, Z. H., Zhang, X., Brideau, A. D., and Lipton, S. A. (1995). Cloning of a gamma-aminobutyric acid type $\mathrm{C}$ receptor subunit in rat retina with a methionine residue critical for picrotoxinin channel block. Proc. Natl. Acad. Sci. U S A 92, 11756-11760. doi: 10.1073/pnas.92.25. 11756

Conflict of Interest: The authors declare that the research was conducted in the absence of any commercial or financial relationships that could be construed as a potential conflict of interest.

Copyright (c) 2020 Barnes, Grove, McHugh, Hirano and Brecha. This is an open-access article distributed under the terms of the Creative Commons Attribution License (CC BY). The use, distribution or reproduction in other forums is permitted, provided the original author(s) and the copyright owner(s) are credited and that the original publication in this journal is cited, in accordance with accepted academic practice. No use, distribution or reproduction is permitted which does not comply with these terms. 